\title{
HOLD OR SELL? \\ HOW CAPITAL GAINS TAXATION AFFECTS HOLDING DECISIONS
}

\author{
Annika Hegemann*, Angela Kunoth\#, Kristina Rupp ${ }^{\dagger}$ and Caren Sureth-Sloane ${ }^{\ddagger}$
}

\begin{abstract}
Investments with exit flexibility require decisions regarding both the investment and holding period. Because selling an investment often leads to taxable capital gains, which crucially depend on the duration of an investment, we investigate the impact of capital gains taxation on exit timing under different tax systems. We observed that capital gains taxation delays exit decisions but loses its decision relevance for very long holdings. Often the optimal exit time, which indicates the maximal present value of future cashflows, cannot be determined analytically. However, we identify the breakeven exit time that guarantees present values exceeding those of an immediate sale. While, after-taxes, an immediate sale is often optimal, long holding periods might also be attractive for investors depending on the degree of income and corporate tax integration. A classic corporate tax system often indicates holdings over more than 100 periods. By contrast, a shareholder relief system indicates the earliest breakeven exit time and thus the highest level of exit timing flexibility. Surprisingly, high retention rates are likely to accelerate sales under a classic corporate system. Additionally, the worst exit time, which should be avoided by investors, differs tremendously across tax systems. For an integrated tax system with full imputation, the worst time is reached earlier than under partial or non-integrated systems. These results could help to predict investors' behavior regarding changes in capital gains taxation and thus are of interest for both investors and tax policymakers. Furthermore, the results emphasize the need to control for the underlying tax system in cross-country empirical studies.
\end{abstract}

Keywords: Capital Gains Taxation, Holding Period, Exit Flexibility, Investment Decisions, Timing Decisions

JEL-Classification: H20, H21, H25

Acknowledgements: Earlier versions of this paper were entitled "Impact of Capital Gains Taxation on the Holding Period of Investments under Different Tax Systems" and "Impact of Capital Gains Taxation on Investment and Holding Decisions under Different Tax Systems". We are grateful for very helpful suggestions by two anonymous reviewers. We thank Stephan Alberternst and Pia Kortebusch for valuable suggestions on an earlier draft. We are particularly grateful to Boqiang Huang for technical support and helpful advices on using MatLab. The usual disclaimer applies. Financial support by the German Research Fund (DFG), project no. SU 501/4-2, and the University of Paderborn is gratefully acknowledged.

\footnotetext{
* University of Paderborn, Faculty of Business Administration and Economics, Warburger Str.100, 33098 Paderborn, Germany. Tel.: ++49-5251-60-1875, email: annika.hegemann@upb.de, www.upb.de/taxation.

\# University of Cologne, Mathematical Institute, Weyertal 86-90, 50931 Köln, Germany. Tel.: ++49-221-470-6080, email: kunoth@math.uni-koeln.de, www.mi.uni-koeln.de/AG-Kunoth/.

† University of Paderborn, Faculty of Business Administration and Economics, Warburger Str.100, Paderborn, Germany. Email: ruppk2@mail.uni-paderborn.de.

‡ University of Paderborn, Faculty of Business Administration and Economics, Warburger Str.100, 33098 Paderborn, Germany. Tel.: ++49-5251-60-1781, email: caren.sureth@upb.de,www.upb.de/taxation and Vienna University of Economics and Business, Vienna, Austria.
} 


\section{CONTENTS}

1 Introduction 1

2 Prior Literature 4

$\begin{array}{llr}3 & \text { Model } & 7\end{array}$

3.1 Tax-free Model . . . . . . . . . . . . . . . . . . . . . . 7

3.2 General Tax Model $\ldots \ldots \ldots$. . . . . . . . . . . . . . 9

4 Holding Decisions $\quad 12$

4.1 Parameter sensitivity . . . . . . . . . . . . . . . . . . . . . . . 12

4.2 Analytical Approach $\ldots \ldots \ldots \ldots$

4.3 Worst Exit Time . . . . . . . . . . . . . . . . . . 20

4.4 Extremes at the Boundaries . . . . . . . . . . . . . . 22

4.5 Numerical Analysis . . . . . . . . . . . . . . . . . . 28

5 Conclusion 33 


\title{
HOLD OR SELL? \\ HOW CAPITAL GAINS TAXATION AFFECTS HOLDING DECISIONS
}

\begin{abstract}
Investments with exit flexibility require decisions regarding both the investment and holding period. Because selling an investment often leads to taxable capital gains, which crucially depend on the duration of an investment, we investigate the impact of capital gains taxation on exit timing under different tax systems. We observed that capital gains taxation delays exit decisions but loses its decision relevance for very long holdings. Often the optimal exit time, which indicates the maximal present value of future cash flows, cannot be determined analytically. However, we identify the breakeven exit time that guarantees present values exceeding those of an immediate sale. While, after-taxes, an immediate sale is often optimal, long holding periods might also be attractive for investors depending on the degree of income and corporate tax integration. A classic corporate tax system often indicates holdings over more than 100 periods. By contrast, a shareholder relief system indicates the earliest breakeven exit time and thus the highest level of exit timing flexibility. Surprisingly, high retention rates are likely to accelerate sales under a classic corporate system. Additionally, the worst exit time, which should be avoided by investors, differs tremendously across tax systems. For an integrated tax system with full imputation, the worst time is reached earlier than under partial or non-integrated systems. These results could help to predict investors' behavior regarding changes in capital gains taxation and thus are of interest for both investors and tax policymakers. Furthermore, the results emphasize the need to control for the underlying tax system in cross-country empirical studies.
\end{abstract}

Keywords: Capital Gains Taxation, Holding Period, Exit Flexibility, Investment Decisions, Timing Decisions

JEL-Classification: H20, H21, H25 


\section{INTRODUCTION}

Entrepreneurial investments are characterized not only by decisions to undertake an investment but also by the holding period. Taxes are well known to be important parameters of the institutional environment of investments (for an overview, see Shackelford and Shevlin 2001; Graham 2008; Hundsdoerfer et al. 2008; Hanlon and Heitzman 2010). Taxes on both the corporate and shareholder levels can significantly affect investment and divestment decisions. Specifically, selling an investment often produces capital gains, inducing capital gains taxes that are anticipated by investors. Capital gains taxes are well-known to induce lock-in effects (Constantinides 1983), thus impeding exits. Capital gains are often due to retained earnings; hence, they crucially depend on the duration of an investment. Because the duration of an investment can affect its after-tax profitability, we investigate the impact of capital gains taxation on the holding period. The relevance of the holding period in investment decisions was emphasized by Alles and Murray (2009), who found a significant impact of holding periods on investment performance for different asset classes, and Cheng et al. (2010), who built on prior empirical studies and theoretically showed that the decision about the time to sell is crucial for real estate investments and their performance. Against this background, the following research questions arise: When should an investor divest? To what extent does capital gains taxation affect exit decisions? Because prior theoretical research has indicated that the manner in which capital gains taxes are embedded in the overall tax system is crucial for their impact on investment (König and Wosnitza 2000; Schreiber and Rogall 2000; Sureth and Langeleh 2007), we distinguish among three tax systems that differ in the degree of the integration of corporate-level taxes into income taxation. To what extent does the underlying tax system impact the effect of capital gains taxation on the holding period? No studies to date have analytically addressed the impact of capital gains taxation in different tax environments on holding periods. We want to fill this gap, and we focus on both different tax systems, including capital gains taxes and tax rate differentials, and on the impact of retention policy.

We take the investor's point of view and focus on investment in corporate shares. After an initial investment, the investor receives dividends and/or capital gains in subsequent periods. In addition to, or alternatively by, investing in a corporation, 
the investor can invest in the capital market and earn interest. Interest, dividends, and capital gains are all considered capital income, but they are typically subject to different tax rules, e.g., different tax scales. We assume symmetric taxation of capital gains and losses. Consequently, profits are subject to the profit tax rate. Losses are tax-deductible at the same tax rate. We focus on the variable "time of sale" to analyze whether the investment becomes more or less profitable under a classic corporate tax system, a full imputation tax system or a shareholder relief tax system for different exit times. Because exit time drives the magnitude of capital gains taxation, it is particularly important to investigate the impact of capital gains taxes on investment decisions. This importance is particularly true, because many countries have implemented capital gains taxes - e.g., Canada imposed capital gains taxation in 1972, Ireland in 1975 and Australia in 1985 - while other countries abolished capital gains taxation between 2000 and 2012, e.g., Cyprus, the Republic of Korea, Slovenia and China. ${ }^{1}$ By contrast, Portugal in 2010 and Austria in 2012 implemented capital gains taxation for long-term gains. ${ }^{2}$ Furthermore, in Germany, since 2009, capital gains are no longer tax-exempt but are generally taxable. ${ }^{3}$

Because the impact of capital gains taxation on timing, i.e., the choice of exit time in a capital gains tax setting with exit flexibility, remains under-researched, we include both ordinary and capital gains taxes in the decision calculus. We focus on investments in non-depreciable assets, such as corporate shares, and we examine theoretically whether there is an optimal exit time, and, if no optimal exit time exists, what would be an appropriate time to sell. Unfortunately, we find that there is no optimal holding period for a present value-maximizing investor. However, we analytically determine the breakeven exit time that guarantees present values exceeding those from immediate sale. Furthermore, we determine the worst exit time that should be avoided by investors. Our analysis is based on theoretical investigations, as well as numerical schemes, elaborated in Rupp (2012). Obviously, if investors are flexible with regard to holding time, it is important that they anticipate the tax differences that might arise from different holding behaviors. We show that an immediate sell-off is often more attractive than short-term holdings. We find that longer holding periods

1 See Carroll et al. (2012), pp. 7-8.

2 See Edwards (2012), p. 1.

3 For an overview of the top marginal tax rates on capital gains of the OECD countries, see, e.g., Pomerleau (2014), p. 7. 
can be beneficial if the investor does not abandon the project at the worst exit time but waits until the breakeven exit time, i.e., until the present value of an immediate sell-off can be recovered. Obviously, capital gains taxation delays exit decisions. Beyond the well-known impact of retention policies, we clarify that the breakeven exit time particularly depends on the degree of income and corporate tax integration. A classic corporate tax system often induces holdings over more than 100 periods. By contrast, a shareholder relief system indicates the earliest breakeven exit time and thus the highest level of exit timing flexibility. Surprisingly, high retention rates are likely to accelerate sales under a classic corporate system. Additionally, the worst exit time, which should be avoided by investors, differs tremendously across tax systems. For an integrated tax system with full imputation, it is reached earlier than under partial or non-integrated systems.

These results help to predict investors' behavior regarding changes in capital gains taxation conditioned on the underlying tax system. Our results are interesting for both investors and tax policymakers.

To answer our research questions, we determine the present value of the future cash flows from investment as a decision criterion. After introducing the relevant literature in section 2, we use Gordon's growth model in section 3 (Gordon and Shapiro 1956; Gordon 1962) as the basic asset pricing model to derive a solution theoretically for the underlying investment decision in section 4 . This model enables us to investigate the impacts of dividends and capital gains taxation on holding decisions. First, we describe the pre-tax model, and then we integrate taxes into the model. To show the differences that arise from three underlying tax systems, we focus on the change in the present value of the investment in each scenario, and we conduct a sensitivity analysis that provides a first impression of the influence of different parameters, e.g., the retention rate. In section 4 , we analytically determine the exit time with the lowest present value for different tax systems. We find that this worst-case exit time varies significantly depending on the underlying tax system, often making an immediate sale optimal. Employing Newton's method as a numerical scheme to find the zeros of the relevant equation, we identify the breakeven exit period, which must be exceeded to obtain present values that are higher than those with an immediate sale. In section 5 , we present the paper's conclusions. 


\section{PRIOR LITERATURE}

Several analytical and empirical studies have investigated the impact of taxation on investment in corporate stocks and asset prices, particularly of the effects that arise from capital gains taxation (Feldstein et al. 1980; Bradford 1981; Stiglitz 1983; Auerbach 1989; Auerbach 1991; Lang and Shackelford 2000; Blouin et al. 2002; Ayers et al. 2003; Guenther and Sansing 2006; Dai et al. 2008; Becker et al. 2013; Campbell et al. 2013). The literature provides evidence that stock prices react to capital gains tax rate changes. Furthermore, there have been empirical studies across different (capital gains) tax systems; e.g., Poterba and Weisbenner (2001) examined U.S. (turn-of-theyear) stock returns across three capital gains tax regimes (a total of 34 years). In their empirical analysis, they found significant differences across these three systems. They explained this observation by individual investors adjusting their trading behavior to the respective tax regime. Another empirical study was conducted by Jacob (2014). Based on a sample of Swedish individuals, he provided evidence that the tax regime, either progressive or proportional, impacts the realization of capital gains. Both studies, Poterba and Weisbenner (2001) and Jacob (2014), accounted for restrictions in the deductibility of capital losses.

Distortive tax effects under different tax regimes with capital gains taxation have also been identified analytically by König and Wosnitza (2000) and Schreiber and Rogall (2000). The latter analyzed the German Corporate Tax Reform of 2001, which abolished the full imputation system and introduced shareholder relief. They found distortions after the tax reform but a reduction in the double taxation of capital gains. König and Wosnitza (2000) used Gordon's growth model to compare the imputation tax system with and without capital gains taxation. They showed that capital gains taxation distorts price formation on the stock market due to temporary double taxation. The result is discrimination of equity investment against debt capital, rendering the founding of businesses more difficult. Moreover, Sureth (2006) and Sureth and Langeleh (2007) identified a distorting effect of capital gains taxes on investment under full imputation, shareholder relief and classic tax systems. Sureth and Langeleh (2007) theoretically investigated the effects of varying degrees of integration of corporate and capital gains tax into income tax and the impacts on investment decisions. Using the growth model, they could not theoretically determine a general solution for 
the investment problem, i.e., the decision to invest in shares or in the capital market under different tax regimes. Only under restrictive assumptions could they find that the shareholder relief tax system induces more severe distortions than the full imputation tax system. In a sensitivity analysis, they investigated the influence of different retention rates, as well as different holding periods, on investment value under an imputation system. They found that the distortive tax effects increase with the retention rate. Moreover, they emphasized the relevance of the time of sale under a capital gains tax. Knoll and Wenger (2007) found that the introduction of a flat tax on dividends particularly discriminates against private domestic equity investors in high tax brackets.

Selling an investment often leads to capital gains disclosures and, consequently, to capital gains taxation. Because capital gains crucially depend on the duration of an investment, we investigate investment decisions with exit flexibility. Despite the body of empirical literature on capital gains taxes and trading behavior (Bogart and Gentry 1995; Ivković et al. 2005; Ayers et al. 2008; Haesner and Schanz 2013) and the body of theoretical studies accounting for loss-offset opportunities in this context (Constantinides 1983; Stiglitz 1983; Nippel and Podlech 2011; Ehling et al. 2013), all of these studies focused on listed corporations. However, little attention has been paid to the impact of capital gains taxation on both investment in corporate shares in general and the holding period under different tax systems.

There is a body of literature on the effects of taxation on investment decisions and holding periods. For example, Protopapadakis (1983) estimated the effective marginal tax rate of capital gains and emphasized the influence of the expected holding period and these expected effective tax rates using U.S. IRS data estimates on average, rather long holding periods of 24 and 31 years. Cook and O'Hare (1987) studied the relationship between holding periods and after-tax rates of return in a capital gains tax setting. They distinguished between finite and infinite (realized at death) durations. A tax rate increase reduces the after-tax rate of return of short-run realizations for finite durations, while the after-tax rate of return of long-run realizations either decreases or increases, depending on the relationship of the investment rate with internal growth. In their empirical investigation, they found evidence that the marginal capital gains tax rate from the year before death does not have a significant impact on capital gains realized at death. In agreement with these findings, Gau and Wang 
(1994), who empirically investigated the determinants of holding period decisions regarding real investment, found that the current market interest rate, consumption, and investment preferences are more important than tax issues. By contrast, Klein (1999) found capital gains taxes to be an important driver of holding decisions. He elaborated a general equilibrium asset pricing model with capital gains taxation that occurs upon realization. He illustrated that the optimal holding of a given stock depends on the individual deferral terms, accrued capital gains and expected holding periods of all investors. König and Wosnitza (2004) determined the optimal economic lifetime of an investment in the presence of taxes given that, in the absence of taxes, the investor is indifferent between selling and holding the investment. They showed that the investor should never sell an investment if selling discloses hidden reserves, i.e., capital gains (and vice versa). ${ }^{4}$ Although they also identifed distortional effects of taxation on holding decisions, in contrast with our study, they assumed exogenously given liquidation proceeds and a depreciable investment object that can be replaced at an optimal point in time. Furthermore, they did not explicitly distinguish among different taxes. Niemann and Sureth (2013) examined the impact of capital gains taxation on investment timing under simultaneous investment and abandonment flexibility. They showed numerically that capital gains taxation accelerates risky investment under specific conditions, e.g., high liquidation proceeds, more conservative tax accounting, low interest rates, and low volatility (Cremer et al. 2010). Jacob (2013) empirically studied the impact of capital gains taxes on holding behavior after the 2001 German Corporate Tax Reform. He provided evidence that capital gains realizations are deferred if marginal income tax rates are high.

To summarize, the existing literature has offered mixed results regarding the impact of taxes on holding and exit decisions. Niemann and Sureth (2013) already illustrated that, under certain conditions, capital gains taxation can accelerate investments in simultaneous entry and exit decisions. In contrast with our study, they neither distinguished among different tax systems nor focused on the impact of profit retention rates, which we identify as important drivers for holding decisions.

4 See König and Wosnitza (2004), pp. 106-126. 


\section{MODEL}

In Gordon's growth model, the present value of investment $V_{0}$ is determined by future dividends $D$, which are generated by the investment project. An investor realizes all investment projects that, in present value terms, earn more than the initial investment outlay. Gordon's growth model is a discrete time model; thus, we examine time $t \in \mathbb{N}_{0}$.

\subsection{TAX-FREE MODEL}

In agreement with these previous studies we assume a private investor A that spends $I_{0}$ on an investment in shares of a corporation. To determine the present value of the investment $V_{0}$, the investor discounts all future dividends $D$ with the exogenously given periodical interest rate $i \in(0,1)$. For example, this interest rate could be easily interpreted as a monthly, quarterly or annual interest rate. The observed time horizon is determined by $t \in \mathbb{N}_{0}$. Profits $P$ arise after one period, starting at $t=1$. The rate of return of the alternative investment in the capital market is denoted by $i .^{5}$ We assume that the capital market is perfect and certain. Therefore, the present value $V_{0}$ can be described as a function of $\gamma$ and $i,{ }^{6}$

$$
V_{0}[\gamma, i]=\sum_{t=1}^{\infty} \frac{D[t, \gamma]}{(1+i)^{t}}
$$

where $\gamma$ denotes the retention rate. Here, dividends $D[t, \gamma]$ are the distributed part of the investment profits $P[t]$. At the firm level, a constant fraction $\gamma \in[0,1]$ of the profits is retained ${ }^{7}$

$$
R[t, \gamma]=\gamma \cdot P[t]
$$

where $R[t, \gamma]$ describes the retained profits in $t$, while distributing the remainder as dividends:

$$
D[t, \gamma]=(1-\gamma) \cdot P[t] .
$$

5 See Gordon and Shapiro (1956), p. 104.

6 See Gordon and Shapiro (1956), p. 104.

7 See Gordon and Shapiro (1956), p. 105. Note, that in the following, we consider $\gamma$ to be exogenously given. Consistent with prior literature, we do not account for information asymmetry or other signaling causes. We further abstract from the retention rate being less sensitive to cash flows if dividend taxes are sufficiently high as suggested by empirical evidence. See, e.g., Jacob and Jacob (2013). 
The profits from the previous period $P[t-1]$ and the return on retained profits serve as the basis for the profits at $t$. The profits of the current period are $P[1]=i I_{0}$. Hence, we obtain

$$
P[t]=(1+\gamma i) \cdot P[t-1]
$$

where, $\gamma i$ is the constant growth rate that characterizes Gordon's growth model, which, in the literature, is typically denoted as $g$.

By assumption, the internal and external rates of return are both equal to $i$. Under this assumption, the underlying investment can only be more attractive than the alternative capital market investment in the case of a (non-neutral) tax system. Consequently, in the absence of taxes, the investor will always be indifferent between the investment in the corporation and the alternative investment.

The investor A holds the investment object for a specific period. At time $t=z$, she or he sells her or his investment to another private investor B at a price $S[z, \gamma, i]$ with $z \geq 0$. On the one hand, if the price is greater than the investment outlay $I_{0}$, the investor earns a capital gain, $G[z, \gamma, i]$.

$$
G[z, \gamma, i]=S[z, \gamma, i]-I_{0}
$$

On the other hand, the investor realizes a capital loss if the price is less than $I_{0}{ }^{8}$ Investor B holds the investment until $T=\infty$. The present value $V_{0}[z, \gamma, i]$ captures all future cash flows; i.e., it contains the discounted cash flow and the discounted price. ${ }^{9}$ We obtain

$$
V_{0}[z, \gamma, i]=\sum_{t=1}^{z} \frac{D[t, \gamma]}{(1+i)^{t}}+\frac{S[z, \gamma, i]}{(1+i)^{z}} .
$$

Finally, we determine the price $S[z, \gamma, i]$, which, for investor $\mathrm{B}$, is determined by the dividends earned after the sale at $t=z$. At the same time, the price is the minimum price that the investor A is willing to accept to sell the investment. In Gordon's growth model, this price for $\mathrm{A}$ and $\mathrm{B}$ is given by ${ }^{10}$

$$
S[z, \gamma, i]=\sum_{t=Z+1}^{\infty} \frac{D[t, \gamma]}{(1+i)^{t-Z}}=I_{0}(1+\gamma i)^{Z}
$$

\footnotetext{
8 See eq. (5).

9 See König and Wosnitza (2000), p. 785; Sureth and Langeleh (2007), p. 315.

10 Determined by applying the geometric series.
} 
The present value $V_{0}[z, \gamma, i]$ is a function of $i$ and thus includes a comparison of the two investment alternatives, namely the real investment in shares and the alternative investment in the capital market. If $V_{0}[z, \gamma, i]$ is greater than $I_{0}$, the real investment is more attractive than the capital market investment. If $V_{0}[z, \gamma, i]$ is smaller than $I_{0}$, the investor prefers the alternative capital market investment. If $V_{0}[z, \gamma, i]$ equals $I_{0}$, the investor is indifferent between the two alternatives. ${ }^{11}$

\subsection{GENERAL TAX MODEL}

In the following, we integrate taxes into the growth model. We model a general tax system, which can be easily transformed into a classic corporate tax system, a full imputation tax system and a shareholder relief tax system. ${ }^{12}$

The profits $P\left[t, \tau^{\mathcal{C}}\right]$ are taxed at the corporate tax rate $\tau^{\mathcal{C}} \in[0,1)$,

$$
P\left[t, \tau^{c}\right]=P[t] \cdot\left(1-\tau^{c}\right)
$$

After corporate taxation, profits can be distributed. The retained fraction is $R\left[t, \gamma, \tau^{\mathcal{C}}\right]=$ $\gamma P[t] \cdot\left(1-\tau^{c}\right)$. The dividend fraction is given by $D\left[t, \gamma, \tau^{c}\right]=(1-\gamma) P[t] \cdot\left(1-\alpha \tau^{c}\right)$. Dividends are subject to shareholder level taxation. Income taxes at rate $\tau$ must be paid on dividends. Depending on the tax system, a fraction of corporate tax is imputable to the income tax. We denote the fraction of corporate tax that cannot be imputed for income tax purposes $\alpha \in[0,1]$, and we obtain

$$
P\left[t, \tau^{\mathcal{c}}\right]=\gamma P[t] \cdot\left(1-\tau^{\mathcal{C}}\right)+(1-\gamma) P[t] \cdot\left(1-\alpha \tau^{\mathcal{c}}\right) .
$$

We restrict $\gamma$ to

$$
\gamma<1 \text { and } \gamma<\frac{i^{T}}{i^{T^{c}}}
$$

for all tax systems. With this restriction, we avoid results that are absurd from an economic point of view. ${ }^{13}$

11 See, e.g., König and Wosnitza (2004), p. 139.

12 See König and Wosnitza (2000) for a model under an imputation system; for a more general approach, see Sureth and Langeleh (2007), pp. 315-317.

13 If we allowed for $\gamma \geq \frac{i^{\tau}}{i T^{c}}$ we would model infinite growth. Infinite growth is unrealistic and excluded from our model for plausibility reasons. See Sureth (2006), pp. 58, 74; Sureth and Langeleh (2007), p. 317. 
At the shareholder level, interest and dividends are subject to income tax at a rate $\tau \in[0,1)$. Investors $\mathrm{A}$ and $\mathrm{B}$ have the same income tax rate. The income tax rate is equal to the personal tax rate of the investor. We assume that capital gains are taxed at a special tax rate $\tau^{g}=\frac{\tau}{2}$. The parameter $\beta \in[0,1]$ denotes the fractions of dividends and capital gains that are subject to income taxation. For simplicity, we abstract from different capital gains the tax rates for short- and long-term capital gains. Moreover, we assume a full and complete capital gains loss offset. Thus, we indicate that capital losses that arise from the underlying project might be immediately offset against positive capital gains generated by other projects. Consequently, whenever a capital loss is incurred, the investor receives a capital tax refund. Furthermore, we refrain from conducting a sensitivity analysis with regard to the capital gains tax rate and its impact on the holding period, because we will show that the critical thresholds for holding decisions are unaffected by the level of capital gains taxation.

In our model, we do not consider any tax privilege regarding interest income. Therefore, the after-tax market rate of return is given by

$$
i^{T}=i \cdot(1-\tau)
$$

Post-income tax dividends are calculated as

$$
D\left[t, \gamma, \tau, \tau^{\mathcal{C}}\right]=(1-\gamma) P[t] \cdot\left(1-\alpha \tau^{\mathcal{C}}\right) \cdot(1-\beta \tau)
$$

The after-tax price amounts to

$$
S\left[z, \gamma, i, \tau, \tau^{c}, \tau^{g}\right]=\sum_{t=Z+1}^{\infty} \frac{D\left[t, \gamma, \tau, \tau^{c}\right]}{\left(1+i^{\tau}\right)^{t-z}}-\left(\sum_{t=Z+1}^{\infty} \frac{D\left[t, \gamma, \tau, \tau^{c}\right]}{\left(1+i^{\tau}\right)^{t-Z}}-I_{0}\right) \cdot \beta \tau^{g} .
$$

First, the after-tax dividends of investor B are discounted to time $\mathrm{z}$. The difference between the discounted dividends and the initial outlay $I_{0}$ is subject to capital gains taxation at a rate $\tau^{g} \in[0,1){ }^{14}$

14 See Müller and Semmler (2003), who use a more complex approach and show theoretically that deferred capital gains taxes on hidden reserves reduce the price that arises from negotiations between seller and buyer. 
The present value after taxation for real investment is given by

$$
V_{0}^{G T}\left[z, \gamma, i, \tau, \tau^{\mathcal{c}}, \tau^{g}\right]=\sum_{t=1}^{z} \frac{(1-\gamma) P[t] \cdot\left(1-\alpha \tau^{\mathcal{C}}\right) \cdot(1-\beta \tau)}{\left(1+i^{\tau}\right)^{t}}+\frac{S\left[z, \gamma, i, \tau, \tau^{\mathcal{C}}, \boldsymbol{\tau}^{g}\right]}{\left(1+i^{\tau}\right)^{z}}
$$

Here, we use GT as a suffix for the present value under the general tax system. Then, based on equation (14), we model three specific tax systems. ${ }^{15}$ The classic corporate tax system, indicated by the suffix $C C$, is given by $\alpha=1$ and $\beta=1$ and, thus, ${ }^{16}$

$$
V_{0}^{C C}\left[z, \gamma, i, \tau, \tau^{\mathcal{C}}, \boldsymbol{\tau}^{g}\right]=\sum_{t=1}^{z} \frac{(1-\gamma) P[t] \cdot\left(1-\tau^{\mathcal{C}}\right) \cdot(1-\tau)}{\left(1+\boldsymbol{i}^{\boldsymbol{\tau}}\right)^{t}}+\frac{S\left[z, \gamma, i, \boldsymbol{\tau}, \boldsymbol{T}^{\mathcal{C}}, \boldsymbol{\tau}^{g}\right]}{\left(1+\boldsymbol{i}^{\boldsymbol{\tau}}\right)^{z}} .
$$

Here, the corporate tax burden is non-refundable.

The shareholder relief tax system, indicated by $S R$, is characterized by $\alpha=1$ and $\beta=0.5$, which indicate that $50 \%$ of dividends and capital gains are assumed to be subject to income taxation ${ }^{17}$

$$
V_{0}^{S R}\left[z, \gamma, i, \tau, \tau^{\mathcal{c}}, \tau^{g}\right]=\sum_{t=1}^{z} \frac{(1-\gamma) P[t] \cdot\left(1-\tau^{\mathcal{c}}\right) \cdot(1-0.5 \tau)}{\left(1+i^{\tau}\right)^{t}}+\frac{S\left[z, \gamma, i, \tau, \tau^{\mathcal{c}}, \tau^{g}\right]}{\left(1+i^{\tau}\right)^{z}} .
$$

The full imputation tax system, indicated by $F I$, is characterized by $\alpha=0$ and $\beta=1$ and is thus given by ${ }^{18}$

$$
V_{0}^{F I}\left[z, \gamma, i, \tau, \tau^{\mathcal{c}}, \tau^{g}\right]=\sum_{t=1}^{Z} \frac{(1-\gamma) P[t] \cdot(1-\tau)}{\left(1+i^{\tau}\right)^{t}}+\frac{S\left[z, \gamma, i, \tau, \tau^{c}, \tau^{g}\right]}{\left(1+i^{\tau}\right)^{z}} .
$$

15 See König and Wosnitza (2000), p. 786; Sureth and Langeleh (2007), p. 322.

16 Under a classic corporate tax system, income and corporate taxes are levied independently on shareholder and company levels. The withholding tax system, which was introduced in Germany in 2009, can be regarded as a classic corporate tax system.

17 E.g., the shareholder relief tax system was introduced in Germany in 2001 and later reformed and accompanied by a flat tax on most types of capital income. Today, the shareholder relief is only rarely applicable. If dividends and capital gains qualify for shareholder relief, then a fraction of $40 \%$ is tax-exempted. The shareholder relief tax system actually still is in force in several countries, e.g., Luxembourg, Norway and France. See BMF (2013), pp. 12-13.

18 In Germany, the full imputation tax system was implemented from 1977 to 2000 . A full imputation tax system is actually present in Malta. See BMF (2013), p. 14. 


\section{HOLDING DECISIONS}

\subsection{PARAMETER SENSITIVITY}

To investigate the holding decision, we use the general form of the present value function, ${ }^{19}$ and in the following, we simplify $D\left[t, \gamma, \tau, \tau^{c}\right]$ to $D_{t}$.

$$
\begin{aligned}
& V_{0}^{\boldsymbol{T}}=\sum_{t=1}^{Z} \frac{D_{t} \cdot\left(1-\alpha \tau^{\mathcal{c}}\right) \cdot(1-\beta \tau)}{\left(1+i^{\boldsymbol{T}}\right)^{t}}+\sum_{t=Z+1}^{\infty} \frac{D_{t} \cdot\left(1-\alpha \tau^{\mathcal{C}}\right) \cdot(1-\beta \tau)}{\left(1+i^{\boldsymbol{T}}\right)^{t}} \\
& -\left(\sum_{t=Z+1}^{\infty} \frac{D_{t} \cdot\left(1-\alpha \tau^{c}\right) \cdot(1-\beta \tau)}{\left(1+i^{\tau}\right)^{t-Z}}-I_{0}\right) \cdot \beta \tau^{g} \cdot\left(1+i^{\tau}\right)^{-Z} \\
& =I_{0} \cdot \frac{(1-\beta \tau)(1-\gamma)\left(1-\alpha \tau^{c}\right)}{(1-\tau)-\gamma\left(1-\tau^{c}\right)}\left(1-\beta \tau^{g} \cdot \frac{\left(1+\gamma i^{T^{c}}\right)^{Z}-\frac{(1-\tau)-\gamma\left(1-\tau^{c}\right)}{(1-\beta \tau)(1-\gamma)\left(1-\alpha \tau^{c}\right)}}{\left(1+i^{\tau}\right)^{Z}}\right) \\
& =I_{0} \cdot \phi \cdot\left(1-\beta \tau^{g} \cdot \frac{\left(1+\gamma i^{T^{c}}\right)^{Z}-\frac{1}{\phi}}{\left(1+i^{\tau}\right)^{Z}}\right) \\
& \text { with } \phi=\frac{(1-\beta \tau)(1-\gamma)\left(1-\alpha \tau^{c}\right)}{(1-\tau)-\gamma\left(1-\tau^{c}\right)} \text {. }
\end{aligned}
$$

The coefficient $\phi$ captures all of the effects that arise from current taxation. By contrast, effects from capital gains taxation are included in the third factor in brackets. The distortion from current taxation $(\phi)$ is driven by the corporate and income tax rates $\tau^{c}$ and $\tau$, the parameters $\alpha$ and $\beta$, which indicate the degree of corporate and income tax integration, respectively, and the retention rate $\gamma$, which indirectly determines the part of the periodical profit that is paid out as dividends. The capital gains tax rate does not enter $\phi$. This separation of effects from current and capital gains taxation enables us to use the coefficient $\phi$ to study the respective effects in detail.

Even if $z=0$, however, we find capital gains taxes can distort the investment decision. Given that $\phi \neq 1$ and $z=0$ we obtain $V_{0}^{\tau} \neq I_{0}$. Thus, non-aligned taxation of current profits at the corporate and investor's levels can generate a non-zero capital gains tax base even for immediate sales. The overall impact of the coefficient $\phi$ on the after-tax present value $V_{0}^{\tau}$ is ambiguous and might, depending on the degree

19 See eqs. (13) and (14), and Sureth and Langeleh (2007), p. 317. 
of integration of corporate taxation into income taxation, either foster or hinder real investments, compared to the default alternative.

To address our research question about the influence of taxes on the exit time, we conduct sensitivity analyses. These numerical investigations provide a first impression of the extent to which the exit time drives the after-tax present value. First, we illustrate the present value for the three tax systems under predefined conditions. In the second step, we vary the retention rates. The retention rate determines the capital gains tax base, which is also determined by the exit time.

For illustrative purposes, we assume a retention rate of $\gamma=0.5$, which can be observed often. ${ }^{20}$ Additionally, the assumed tax rates, $\tau=0.4, \tau^{\mathcal{c}}=0.4$ and $\tau^{g}=\frac{\tau}{2}$, are based on real-world tax rates and are, e.g., similar to the top marginal income and corporate tax rates in Germany in $2000 .{ }^{21}$ Furthermore, we assume a pre-tax interest rate of $i=0.1 .^{22}$

Figure 1 provides an overview of the present values under three tax systems depending on time $t=z$. This figure depicts the present value with capital gains taxation $\left(V_{0}^{\tau}\right)$ and without capital gains taxation $\left(I_{0} \cdot \phi\right)$. In the following, for the after-tax present value $V_{0}\left[z, \gamma, i, \tau, \tau^{c}, \tau^{g}\right]$ we write for simplicity $V_{0}^{\tau}$, and the after-tax price at time $z$, previously denoted by $S\left[z, \gamma, i, \tau, \tau^{c}, \tau^{g}\right]$, is simplified to $S_{Z}^{\tau}$.

While the present value without capital gains taxation $I_{0} \phi$ does not depend on time $t=z$, under all three tax systems, considering capital gains, taxation $V_{0}^{\boldsymbol{T}}$ generates a non-linear function of $z$. Hence, there is an obvious time effect caused by capital gains taxation. Capital gains taxation affects the exit time and, hence, the after-tax present value of a project. We observe two reciprocal effects. On the one hand, there is a strong growth effect: the later the exit occurs, the greater the capital gains are (taxable base) because retained earnings increase over time. On the other hand, for late exits, the capital gains tax is relatively low because the tax is paid upon realization. Thus, the discount effect reduces the tax payment in present value terms, especially for late exits. If one effect perfectly outweighs the other, there will be no minimum, and

20 See Halberstadt et al. (2009), p. 376.

21 For an overview of various tax rates in OECD countries, see OECD (2014) and, e.g., Schanz and Schanz (2011), pp.146-154.

22 An interest rate of $i=0.1$ is often used in analytical research. However, because currently interest rates are significantly lower, we conducted sensitivity analyses for lower rates, as well. 


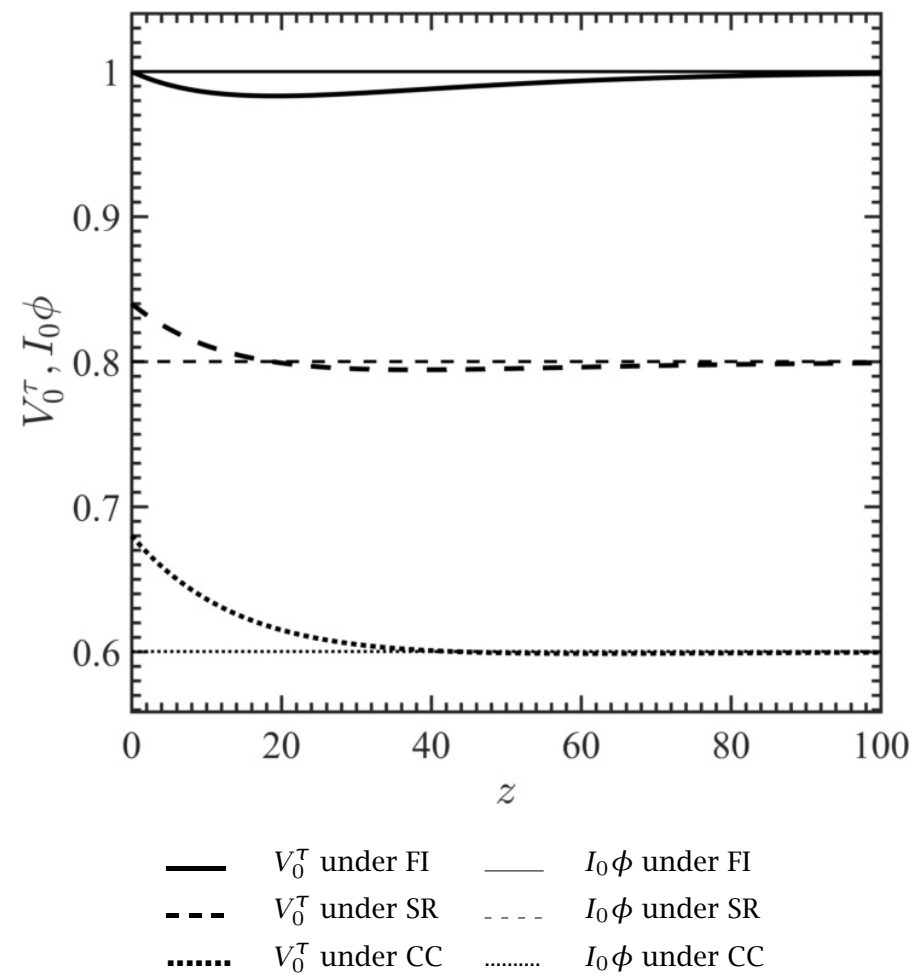

Figure 1: After-tax present value $V_{0}^{\tau}$ depending on the time of sale $z$ with $I_{0}=1, \tau^{c}=0.4$, $\tau=0.4$ and $\gamma=0.5$

the present value will monotonically increase or decrease in $z$. If the two effects do not perfectly balance, a minimum can be found because the invested funds grow at a specific rate $\gamma i$ over time (see eq.(4)) while the capital gains tax base (see eq.(13)), i.e., the difference in the present value of accumulated future dividends at time $z$ and the investment outlay, $\sum_{t=Z+1}^{\infty} \frac{D\left[t, \gamma, \tau, \tau^{c}\right]}{\left(1+i^{\tau}\right)^{t-Z}}-I_{0}$ (capital gains), has to be discounted at another rate, i.e., the after-tax capital market rate. ${ }^{23}$ Therefore, the present value after taxes decreases to a minimum value (growth effect). For later exit times $z$, the capital gains tax is paid later, and the tax payments have less impact on the present value (discount effect). After a minimum value is reached, the discount effect exceeds the growth effect, and the curve increases until the capital gains tax converges to zero.

If there is no capital gains tax, then $V_{0}^{\tau}$ reduces to $I_{0} \phi=V_{0}^{\tau}$. Figure 1 shows that the present value converges asymptotically to the present value without capital gains

23 The opposing effects from these two growths processes can be clarified by taking a look at the underlying type of functions. This type of function has the form $\left(I_{0} e^{w t}-I_{0}\right) e^{-i_{\tau} t}$ where $w$ is the above-mentioned after-tax specific growth rate that may differ from $i_{\tau}$. For illustrative purposes, we use the continuous-time form. For this kind of function, global extrema can be found. 
taxation over the long run. This pattern holds for all three tax systems. ${ }^{24}$ We conduct sensitivity analyses with respect to the underlying interest rate $i$ and find that constellations with $V_{0}^{\tau}<1$ for low interest rates occur more often than for the relatively high rate of $i=0.1$. That is, an investor will more often refrain from undertaking investment in capital stocks under low capital market rates of return. We find that lower interest rates slightly reduce the magnitude but do not change the general direction or characteristics of the identified effects. ${ }^{25}$

Under both the shareholder relief tax system and the classic corporate tax system, the present value with capital gains taxation is greater than the present value without capital gains taxation for early exits. This relation is due to a capital loss tax refund. A capital loss results if the price after corporate and income taxes falls below the initial outlay, i.e., $\sum_{t=Z+1}^{\infty} \frac{D\left[t, \gamma, \tau, \tau^{c}\right]}{\left(1+i^{\tau}\right)^{t-z}}-I_{0}<0$. Corresponding to the previously described scenarios with capital gains, a capital loss may occur even for an immediate sale, i.e., if $z=0$. This is true if corporate and income taxes are fully integrated, hence, for tax systems other than a full imputation system. However, such an investment is characterized by $V_{0}^{T}<1$ and would not be completed because the alternative investment in the capital market is more attractive to the investor. ${ }^{26}$ In our subsequent analyses, we will exclude investments with present values below one, i.e., negative net present values. ${ }^{27}$ Nevertheless, for now, we use this setting to elaborate the forces at work. If $z=0$, we invest and divest in the same period. When we invest $I_{0}$ in all of these tax systems, our return differs. This distortion is due to the interplay of dividends, interest effects, corporate tax rates, and retention rates. We find a tradeoff under full imputation, whereas discrimination against investments in corporate shares compared to alternative investments arises under the other two systems. Even for $z=0$, there is a tax refund for capital losses under the shareholder relief and classic corporate tax systems caused by these distortive effects from current taxation (see figure 1).

24 See Sureth and Langeleh (2007), p. 320, for the full imputation tax system. Extending their study, we show the development for all three different tax systems over time.

25 The worst exit time $z^{\text {min }}$ is increasing in $i$ under all three tax systems. Additionally, we find the breakeven exit time $z^{g}$ increasing in the interest rate in the numerical analysis of the interest sensitivity of $V_{0}^{\tau}>1$. See sections 4.3 and 4.4 for further explanations about the worst exit time and breakeven exit time.

26 Investors will refrain from investment particularly in a setting with certainty concerning all future cash flows.

27 The investor would only carry out the investment if she or he is at least indifferent between the investment and the alternative financial investment. 
Figure 2 illustrates the present values $V_{0}^{\tau}$ for different retention rates $\gamma$ under a full imputation tax system. ${ }^{28}$

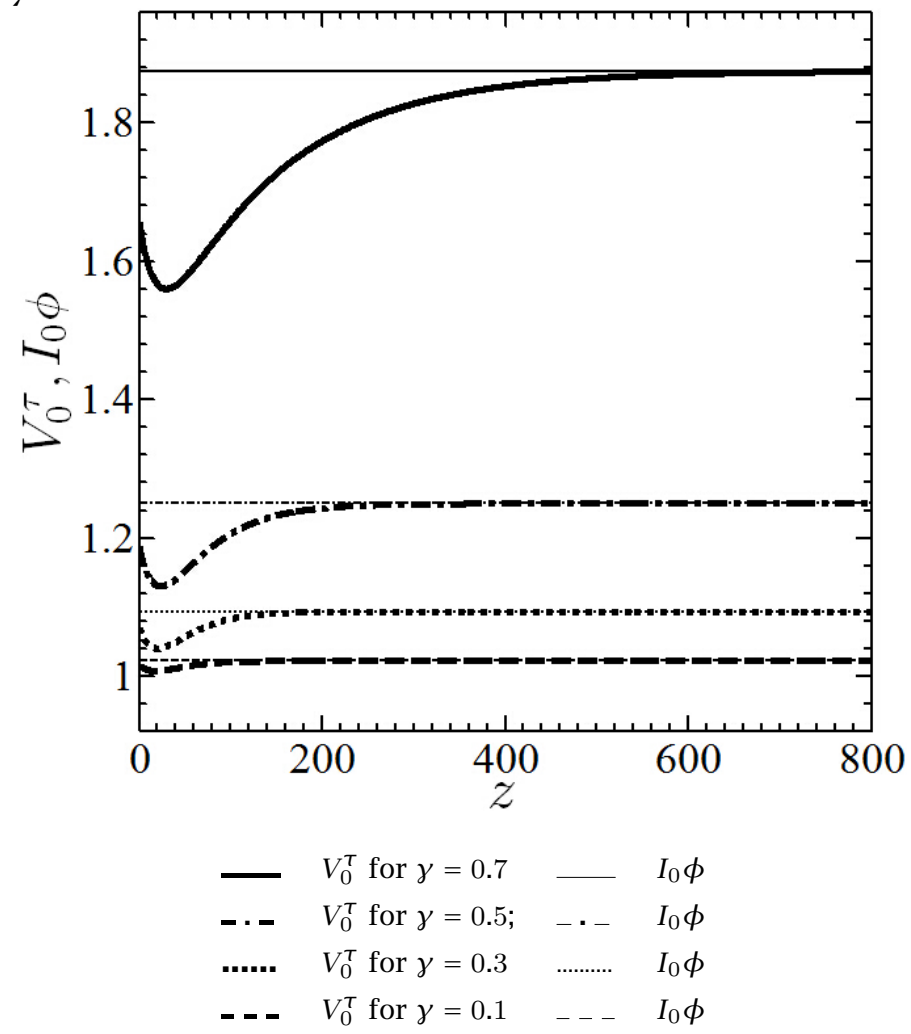

Figure 2: After-tax present value $V_{0}^{\tau}$ depending on the retention ratio $\gamma$ under the full imputation system with $I_{0}=1, \tau^{c}=0.4$ and $\tau=0.5$

The higher the retention rate $\gamma$, the more pronounced the curvature of the present value function and the greater the difference between $\phi$ and $V_{0}^{T}$. This relation is essential for the pronounced impact of capital gains taxation for high retention ratios. Especially for early exit times $z$, the curvature of the graph is strong. ${ }^{29}$ The effect of capital gains taxation for high retention ratios is visible for late exit times, as well. However, for low retention ratios it only affects early exit times. In figure 2, for a retention rate of $\gamma=0.7$, the influence of capital gains taxation is visible until $z=500$, while for a retention rate of $\gamma=0.1$, this effect occurs only until approximately $z=$ 80. For long-term investment the decision relevance of capital gain taxes vanishes. Hence, this finding indicates that the investor should consider capital gains taxation particularly for short holding periods in decision making.

28 See Rupp (2012), p. 37.

29 If the capital gains taxation is paid early, the influence on the present value after taxes $V_{0}^{\tau}$ is strong. The discount effect is very weak for early exit times $z$. 
In addition to the characteristics of the tax systems (FI, SR, CC) and the retention rate $\gamma$, tax rates influence the present value after taxes for various exit times $z$. Therefore, we vary the tax rates in our sensitivity analysis, because the tax rates are exposed to multiple changes by tax reforms and severely affect our results. ${ }^{30}$

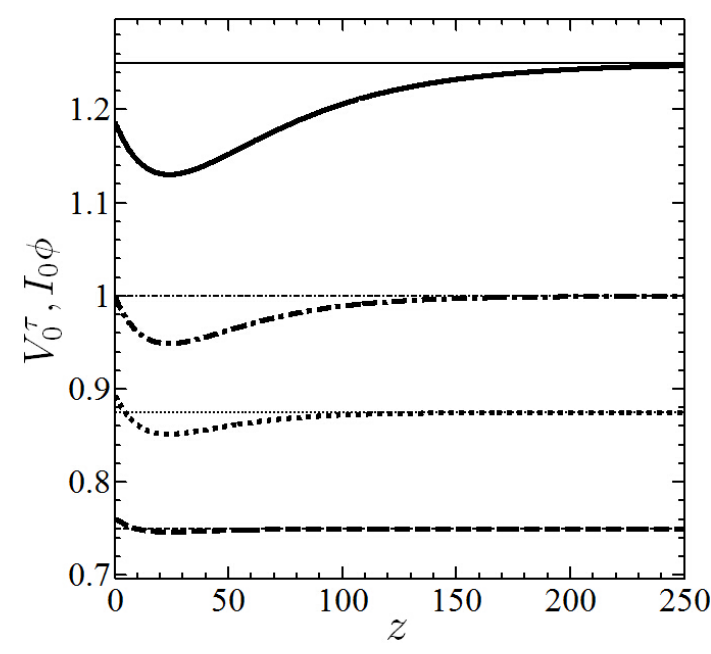

Figure 3: After-tax present value $V_{0}^{\top}$ depending on the income tax rate $\tau$ under the full imputation system with $I_{0}=1, \tau^{c}=0.4$ and $\gamma=0.5$

$$
\begin{aligned}
& -V_{0}^{\top} \text { for } \tau=0.5-I_{0} \phi \\
& \text {-... } \quad V_{0}^{\tau} \text { for } \tau=0.4 \quad \ldots . . \quad I_{0} \phi \\
& \ldots . . . . \quad V_{0}^{\top} \text { for } \tau=0.3 \quad \ldots \ldots \ldots \ldots . . . \quad I_{0} \phi \\
& \text { - _. } \quad V_{0}^{\top} \text { for } \tau=0.1 \ldots I_{0} \phi
\end{aligned}
$$

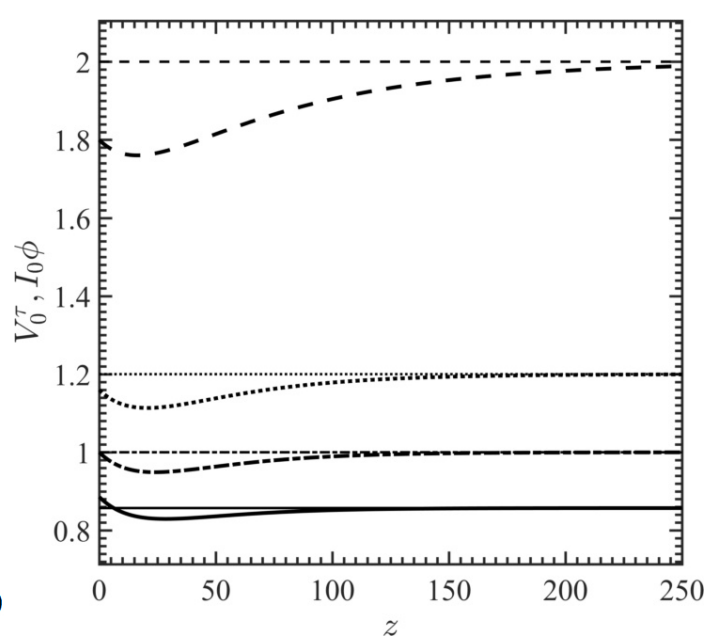

Figure 4: After-tax present value $V_{0}^{\tau}$ depending on the corporate tax rate $\tau^{c}$ under the full imputation system with $I_{0}=1, \tau=0.4$ and $\gamma=0.5$

$$
\begin{aligned}
& \longrightarrow \quad V_{0}^{\top} \text { for } \tau^{\mathcal{c}}=0.1-I_{0} \phi \\
& \text {-... } \quad V_{0}^{\tau} \text { for } \tau^{c}=0.3 \quad \ldots . . \quad I_{0} \phi \\
& \text {...... } V_{0}^{\tau} \text { for } \tau^{\mathcal{c}}=0.4 \quad \ldots \ldots \ldots \ldots . . . \quad I_{0} \phi \\
& \text { - . - } V_{0}^{\top} \text { for } \tau^{\mathcal{C}}=0.5 \ldots \ldots I_{0} \phi
\end{aligned}
$$

Figure 3 (left hand side) illustrates the after-tax present value as a function of $z$ for various income tax rates $\tau$, and figure 4 (right hand side) displays the after-tax present value as a function of $z$ for various corporate tax rates $\tau^{c}$. We plot the results for the full imputation tax system as an example of our analysis. ${ }^{31}$

The same curve characteristics that are already known from figures 1 and 2 can be observed. ${ }^{32}$ The tax rates have an opposite influence on the after-tax present values. While an increasing income tax rate $\tau$ in figure 3 increases the value of $V_{0}^{\tau}$, an increasing corporate tax rate reduces $V_{0}^{\tau}$. If the income tax rate $\tau$ increases, the alternative investment in the capital market is most affected. Interest payments are fully taxed, as

30 For example the business tax reform 2008 in Germany and the tax reform 2000 in Germany.

31 See Sureth (2006), pp. 82-84, Sureth and Langeleh (2007), p. 320, and Rupp (2012), p. 36.

32 The curvature is driven by the growth and the discount effect. 
are the current earnings from the investment in shares, i.e., dividends ${ }^{33}$. By contrast, capital gains, by assumption, are only subject to halved income tax rate, i.e., $\tau^{\mathfrak{g}}=\frac{\tau}{2}$. The slope of the curve is more pronounced at higher income tax rates because capital gains taxation increases proportionally with the income tax rate. This result is in line with Jacob (2013), who finds empirical evidence for deferred capital gains realizations under German shareholder relief if marginal income tax rates are high. ${ }^{34}$

An increase in corporate tax rate $\tau^{\mathcal{C}}$ in figure 4 leads to a decrease of $V_{0}^{\tau}$ because retained earnings are reduced and weaken internal growth. ${ }^{35}$ As a result, the after-tax present value decreases. The slope of the curve is more pronounced for lower corporate tax rates because capital gains are higher and therefore have greater influence on the present value.

In summary, an investor must especially consider high income tax rates $\tau$ and low corporate tax rates $\tau^{\mathcal{C}}$ when deciding on exit time $z$ because the present value of the investment is particularly sensitive to these parameters.

\subsection{ANALYTICAL APPROACH}

Until now, our conclusion, exactly as in prior research, has been restricted to the underlying numerical examples. To improve the explanatory power of our results, in the next step, we aim to determine the optimal exit time in a theoretical fashion.

In the following, we study $V_{0}^{\tau}$ under three tax regimes with capital gains taxation. We use the first derivative to calculate the extreme values of the present value equation with regard to $z$. If we find a maximum, we have identified the optimal exit time, that is, the value at which $V_{0}^{T}$ is highest.

For our analytical calculation, we set all of the variables, except for $z$, and we assume that the function for the present value of the investment can be continuously differentiated. We set

$$
V_{0}^{\tau}[z]:=V_{0}^{\tau}\left[z, \gamma, \tau, \tau^{c}, \tau^{\mathcal{g}}, i\right] .
$$

33 Dividends are also fully subject to the income tax rate.

34 Note that he uses data from 2001 and 2004 where short-term capital gains were tax-exempted.

35 For empirical evidence on the impact of the corporate tax rate on investment, see, e.g., Brandstetter and Jacob (2014) and Diller and Theelen (2014). 
To determine the optimal exit time we use eq. (19) and the first and the second derivatives of $V_{0}^{\boldsymbol{T}}$ with regard to $z^{36}$

$$
\frac{d}{d z} V_{0}^{\tau}[z]=-I_{0} \cdot \phi \cdot \beta \tau^{g} \cdot \frac{\left(\ln \left(1+\gamma i^{\tau c}\right)-\ln \left(1+i^{\tau}\right)\right) \cdot\left(1+\gamma i^{\tau c}\right)^{Z}+\ln \left(1+i^{\top}\right) \cdot \frac{1}{\phi}}{\left(1+i^{\tau}\right)^{Z}}
$$

$\frac{d^{2}}{d z^{2}} V_{0}^{\tau}[z]=-I_{0} \cdot \phi \cdot \beta \tau^{g} \cdot \frac{\left(\ln \left(1+\gamma i^{\tau c}\right)-\ln \left(1+i^{\tau}\right)\right)^{2} \cdot\left(1+\gamma i^{T c}\right)^{Z}-\left(\ln \left(1+i^{\top}\right)\right)^{2} \cdot \frac{1}{\phi}}{\left(1+i^{\top}\right)^{Z}}$

The necessary condition for the optimum is given by:

$$
\frac{d}{d z} V_{0}^{\tau}[z]=-I_{0} \cdot \phi \cdot \beta \tau^{g} \cdot \frac{\left(\ln \left(1+\gamma i^{\tau c}\right)-\ln \left(1+i^{\tau}\right)\right) \cdot\left(1+\gamma i^{\tau c}\right)^{Z}+\ln \left(1+i^{\tau}\right) \cdot \frac{1}{\phi}}{\left(1+i^{\tau}\right)^{Z}} \stackrel{!}{=} 0 .
$$

Because $I_{0}>0, \beta>0, \tau^{g}>0$, and $\left(1+i^{\tau}\right)^{Z}>0$ by definition ${ }^{37}$, we must examine whether $\phi$, with

$$
\phi=\frac{(1-\beta \tau)(1-\gamma)\left(1-\alpha \tau^{\mathcal{C}}\right)}{(1-\tau)-\gamma\left(1-\tau^{\mathcal{C}}\right)}
$$

is positive or negative. The numerator in equation (23) is always greater than zero. This value is true as $(1-\beta \tau)>0$ because $\beta \in[0,1]$, and $\tau \in[0,1) ;(1-\gamma)>0$ because $\gamma \in[0,1)$; and $\left(1-\alpha \tau^{c}\right)>0$ because $\alpha \in[0,1]$ and $\tau^{c} \in[0,1)$. The denominator of the fraction is greater than zero if

$$
(1-\tau)-\gamma\left(1-\tau^{c}\right)>0 \Longleftrightarrow \gamma<\frac{1-\tau}{1-\tau^{c}}
$$

While in equation (10), we have assumed that $\gamma<\frac{i_{\tau}}{i_{\tau_{C}}}$, the denominator is positive and thus $\phi>0$. We simplify equation (22) to $^{38}$

$$
0=\left(\ln \left(1+\gamma i^{T c}\right)-\ln \left(1+i^{\tau}\right)\right) \cdot\left(1+\gamma i^{\tau c}\right)^{Z}+\ln \left(1+i^{\tau}\right) \cdot \frac{1}{\phi}
$$

36 See Rupp (2012), pp. 29-30.

37 We have defined $\beta$ with $\beta \in[0,1]$. For the underlying tax systems, $\beta$ is set either equal to 0.5 or 1 and always greater than zero.

38 See Rupp (2012), pp. 31-32. 
and solve the equation with regard to $\mathrm{z}$

$$
Z=\frac{\ln \left(\frac{-\ln \left(1+i_{\tau}\right)}{\ln \left(\frac{1+\gamma i_{\mathcal{T}}}{1+i_{\tau}}\right)} \cdot \frac{1}{\phi}\right)}{\ln \left(1+\gamma i_{\tau_{c}}\right)} .
$$

Equation (26) describes the exit time $z$ that fulfills the necessary condition in equation (22). To determine whether it is a maximum or a minimum, we must examine the second derivative:

$\frac{d^{2}}{d z^{2}} V_{0}^{\tau}[z]=-I_{0} \cdot \phi \cdot \beta \tau^{g} \cdot \frac{\left(\ln \left(1+\gamma i^{\tau c}\right)-\ln \left(1+i^{\tau}\right)\right)^{2} \cdot\left(1+\gamma i^{\tau c}\right)^{Z}-\left(\ln \left(1+i^{\tau}\right)\right)^{2} \cdot \frac{1}{\phi}}{\left(1+i^{\tau}\right)^{Z}}$

Given that $I_{0}>0, \phi>0, \beta \tau^{g}>0$ and $\left(1+i^{\tau}\right)^{Z}>0$, in the final step, we investigate whether the numerator in equation (21) is negative and, thus, whether

$$
\left(\ln \left(1+\gamma i^{\top c}\right)-\ln \left(1+i^{\tau}\right)\right)^{2} \cdot\left(1+\gamma i^{\tau c}\right)^{Z}-\left(\ln \left(1+i^{\tau}\right)\right)^{2} \cdot \frac{1}{\phi}<0
$$

Because all of the parts of inequality (27) are negative, we can simplify it to:

$$
1<\frac{\left(\ln \left(1+i^{\top}\right)\right)^{2} \cdot \frac{1}{\phi}}{\left(1+\gamma i^{\tau c}\right)^{Z} \cdot\left(\ln \left(1+\gamma i^{\top c}\right)-\ln \left(1+i^{\top}\right)\right)^{2}} .
$$

After transposing the inequality, it is obvious that the right hand side of inequality (28) is greater than zero. Overall, the second derivative is positive. Hence, because the function is strictly convex, the extreme value is a global minimum. A global maximum does not exist.

Although we cannot determine the optimal exit time, our results (see eq. (28)) indicate that there is a worst time to exit, i.e., the time that generates the minimum present value. ${ }^{39}$

\subsection{Worst EXIT Time}

The worst exit time, in the following denoted by $z^{m i n}$, is interesting for the investor because she or he should avoid selling the investment at this time or close to this time. In other words, she or he must minimize the possibility of a liquidity squeeze especially during this time of sale because then the lowest present value would be

39 See also figure 2. 
realized. Figure 5 displays the exit times with the lowest present values for different retention ratios for the three underlying tax systems. ${ }^{40}$

For small retention ratios, the worst exit time $z^{\text {min }}$ significantly depends on the respective tax system, as shown in Figure 5. For high retention ratios, the worst exit times are very similar for all three tax systems. High retention rates indicate a large amount of retained earnings and thus high capital gains and a relatively large weight in overall taxes of capital gains taxes, while a low retention rate indicates low capital gains taxes but instead relatively high weight of taxes on dividend payouts. Figure 5 illustrates that dividend taxation, which is pronounced under low retention rates, induces greater deviations across the underlying tax systems than capital gains taxation. This result holds for all tax rate relations, i.e., $\tau^{\mathcal{C}}=\tau, \tau^{\mathcal{C}}<\tau$ and $\tau^{\mathcal{C}}>\tau$. For a low retention rate of $\gamma=0.1$, the worst exit time is reached after 18 periods under the full imputation tax system, while it requires 104 (55) periods in the classic corporate (shareholder relief) tax system. For a high retention rate $(\gamma=0.9)$, the worst exit times are reached after 44 periods (FI), 54 periods (CC), and 49 periods (SR).

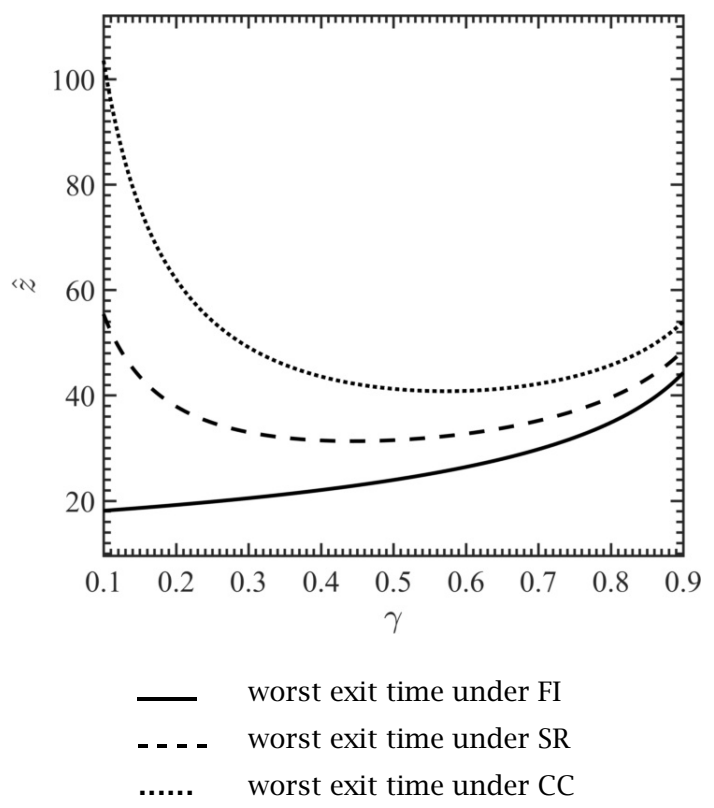

Figure 5: Worst exit time $z^{\text {min }}$ depending on the retention rate $\gamma$ with $\tau^{c}=0.4$ and $\tau=0.4$

We conclude that the type of tax system is particularly important for the holding decision if the dividend rate is sizable. Against this background, especially in coun-

$40 \tau^{c}=0.4 ; \tau=0.4$ 
tries with tax systems that are volatile, the investor should be aware that the worst exit time $z^{\text {min }}$ can change tremendously after substantial tax reform. Prior studies have clarified that the tax systems in many countries often change. ${ }^{41}$ If a corporation that is situated in a country with a volatile tax system distributes most of its profits (sizable dividend rate), changes in the tax system can change their exit timing because the reform is likely to change the worst and avoidable exit times. Furthermore, dividend rates between $27 \%$ and $61 \%$, on average (i.e., relatively high retention rates), can be observed in several countries. ${ }^{42}$ Some empirical studies have provided evidence that dividend ratios tend to increase every year. ${ }^{43}$ By contrast, other studies have indicated, on average, a decrease in the dividend payout. Nevertheless, their findings have indicated that “... larger firms, firms with higher profitability, and firms with lower growth opportunities have a greater propensity to pay dividends." ${ }^{44}$ Using German stock exchange indices ${ }^{45}$ as an example shows that some DAX- and MDAX-listed firms have especially high dividend ratios (approximately 70\% of DAX-listed firms have a dividend rate greater than $35 \%$, and $30 \%$ have a ratio greater than $65 \%$ ). In other countries, e.g., Australia, a dividend rate of more than $2 / 3$ of their stock performance, on average, can be observed. ${ }^{46}$ In countries with such high payout rates, it is even more important to account for the holding implications of possible tax reforms.

\subsection{EXTREMES AT THE BOUNDARIES}

Until now, we have determined the extreme values of the present value function. It was found that there is only a global minimum, that is, the worst time to sell shares. This point in time depends on the underlying tax system and is especially sensitive to high dividend rates. To determine the point of time that is the best exit time, we examine the boundaries of equation (19). The present value functions under all three

41 E.g., Becker et al. (2013) investigate the effect of payout taxes on the allocation of investment and report on the tax regimes across 25 countries between 1990 and 2008. Among these countries, 13 changed their tax system within the observed period. Spain and Mexico even have two variations of their tax systems. See Becker et al. (2013), p. 6.

42 See ap Gwilym et al. (2006), p. 39, who provide a descriptive overview over the payout ratios between 1965/1973/1990-2004 of eleven countries that are considered representative for the industrialized world.

43 See ap Gwilym et al. (2006), pp. 38-39.

44 Fatemi and Bildik (2012), p. 677.

45 See Frère et al. (2012), p. 4.

46 See Frère et al. (2012), p. 14. 
tax systems are convex; thus, the highest present values emerge at the boundaries. Given that, at the left hand side boundary, $z=0$, we observe a local maximum, we investigate the development for $z>z^{\min }$. ${ }^{47}$ We want to determine whether a present value that exceeds the local maximum at $z=0$ can be achieved for sales at time $z>Z^{\text {min }}$.

For example, in figure 1, we illustrate that the local maximum of the present value occurs at $z=0$ for all tax systems. Note that, in this figure, we only depict a finite time horizon of $T=100$. Here, the present value decreases with later exit times until a minimum present value (the worst exit time) is attained. For later exits, the present value increases again, but it does not exceed the initial present value at $z=0$ until $Z=T=100$. Additionally, figure 1 illustrates that the present value with capital gains taxation seems to converge asymptotically toward the present value without capital gains.

To study these effects in greater detail, we determine the general conditions under which a local extreme that exceeds the present value at $z=0$ can be reached. ${ }^{48}$ Here, we examine which of the local extremes (of the boundaries) is the global maximum. For this purpose, we analytically compare the present value at $z=0$ with the present value at $z=T$. At $Z=0$, the present value equation is:

$$
V_{0}^{\tau}[z=0]=I_{0} \phi\left(1-\beta \tau^{\mathfrak{g}} \cdot\left(1-\frac{1}{\phi}\right)\right)
$$

For $z=T$, the present value equation becomes

$$
V_{0}^{\mathcal{T}}[z=T]=I_{0} \phi \cdot\left(1-\beta \tau^{g} \cdot \frac{\left(1+\gamma i^{T^{c}}\right)^{T}-\frac{1}{\phi}}{\left(1+i^{\tau}\right)^{T}}\right)
$$

Depending on $T$, we obtain:

$$
V_{0}^{T}[z=0] \lesseqgtr V_{0}^{T}[z=T]
$$

If the investor sells extremely late, i.e., $(z \rightarrow \infty)$, the present value converges to

$$
\lim _{Z \rightarrow \infty} V_{0}^{\tau}=I_{0} \phi
$$

$47 Z^{\text {min }}$ denotes the exit time $z$ where the global minimum is reached.

48 See Sureth and Langeleh (2007), pp. 320-321, and Rupp (2012), pp. 34-41. 
i.e., the present value without capital gains taxation. ${ }^{49}$ For the last term, which appears in brackets in equation (30), we obtain the capital gains tax multiplier:

$$
\lim _{z \rightarrow \infty} \frac{\left(1+\gamma i^{\tau^{c}}\right)^{z}-\frac{1}{\phi}}{\left(1+i^{\tau}\right)^{z}}=0
$$

The multiplier converges to zero. This finding indicates that the maximum present value at the right boundary is independent of capital gains taxation. This result is robust for all of the investigated tax systems with capital gains taxation, i.e., for different tax rates and retention rates. The maximum reachable present value of the right boundary is $I_{0} \phi$, which is equal to the present value without capital gains taxation. ${ }^{50}$ We denote the earliest exit time, which reaches a present value of $I_{0} \phi$ with $z^{\max }$. Then, equation (30) simplifies to

$$
V_{0}^{T}\left[T=z^{\max }\right]=I_{0} \phi
$$

Figure 6 depicts the exit time $z^{\max }$.

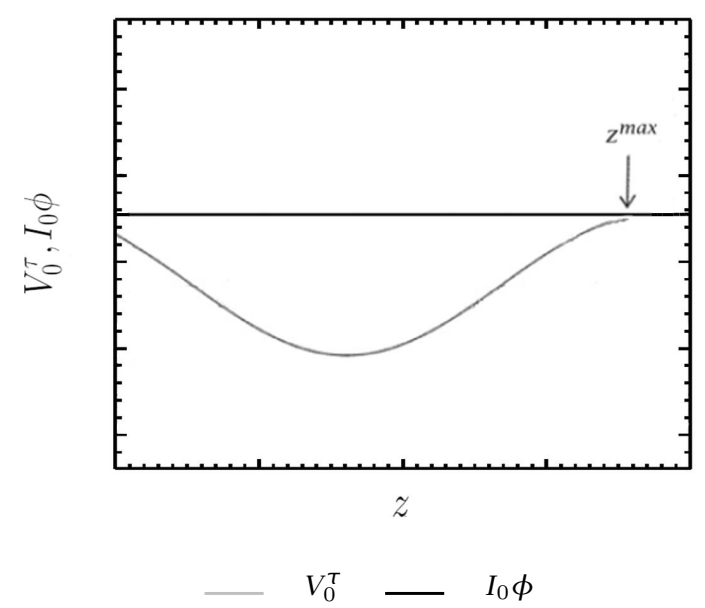

Figure 6: $z^{\max }$ depending on the time of sale $z$ if $\phi>1$

In the following, we compare $V_{0}^{\tau}[z=0]$ with $V_{0}^{\tau}\left[z=z^{\max }\right]=I_{0} \phi\left[z=z^{\max }\right]$ to determine which of the local extremes is the global maximum and, thus, the exit time

\footnotetext{
49 See figure 6.

50 Because it is a matter of a limit value of $V_{0}^{\tau}$, there is an error of $1 e-8$. See eq. (33).
} 
with the highest present value. Hence, we concentrate on the difference between the local extrema. If the right extreme value is the global maximum, we have:

$$
V_{0}^{\tau}[z=0]=I_{0} \cdot \phi\left(1-\beta \tau^{g} \cdot\left(1-\frac{1}{\phi}\right)\right)<I_{0} \cdot \phi\left[z=z^{\max }\right] .
$$

Inequality (36) describes the difference of the local extrema, which reflects the capital gains taxation and respective capital loss tax refund for an exit at $z=0$.

$$
0<\beta \tau^{g}\left(1-\frac{1}{\phi}\right)
$$

If $\beta \tau^{\mathfrak{g}}>0$, the following condition holds:

$$
\phi>1 .
$$

If $\phi>1$, which indicates that the income tax rate is greater than the corporate tax rate, inequality (35) is satisfied. Under capital gains taxation, we obtain the highest present value for $V_{0}^{\tau}$ if the investor sells late, i.e., at $z=z^{\max } .{ }^{51}$

We find that, if $\phi>1$, the global maximum value is reached at $z=z^{\max }$. Thus, the following relationship holds:

$$
V_{0}^{\tau}\left[z=z^{m a x}\right]=\left.V_{0}^{\tau}[z]\right|_{\tau^{g}=0}
$$

It is interesting to determine whether there is an exit time $z=z^{\max }$ that leads to identical present values for investments with capital gains taxation $\left(V_{0}^{\boldsymbol{T}}\right)$ and without capital gains taxation $\left(I_{0} \cdot \phi\right)$. At this exit time, capital gains taxation is irrelevant. For any other holding period, the investor must consider capital gains taxation in his or her investment decision. To determine $z^{\max }$, we set the two present value functions equal and obtain:

$$
\begin{aligned}
I_{0} \cdot \phi & =I_{0} \cdot \phi \cdot\left(1-\beta \tau^{g} \cdot \frac{\left(1+\gamma i^{\tau^{c}}\right)^{z^{\max }}-\frac{1}{\phi}}{\left(1+i^{\tau}\right)^{z^{\max }}}\right) \\
\Leftrightarrow \quad 0 & =\frac{\left(1+\gamma i^{\tau^{c}}\right)^{z^{\max }}-\frac{1}{\phi}}{\left(1+i^{\tau}\right)^{z^{\max }}} .
\end{aligned}
$$

51 If $\phi<1$, then the inequality $0>\beta \tau^{g}\left(1-\frac{1}{\phi}\right)$ is satisfied. The capital loss tax refund for $V_{0}^{\tau}[z=0]$ leads to the highest present value if the investor sells immediately at $z=0$. 
However, we cannot theoretically determine $z^{\max }$ from this equation. In fact, the denominator of equation (39) is greater than zero. ${ }^{52}$ Thus, multiplying by the nonvanishing denominator and writing $\phi$ on one side, equation (39) holds if and only if:

$$
\phi=\frac{1}{\left(1+\gamma i^{T^{c}}\right)^{z^{\max }}} .
$$

Because the second summand on the right hand side is always non-negative, only $\phi \leq 1$ is possible. Consequently, this investment project will not be completed by the investor because its net present value is negative. For this scenario, the highest present value of the investment can be achieved for a sell-off at $z=0$. At $z=0$, the investor realizes a capital loss and receives a tax refund. However, the investment with $\phi<1$ would be rejected by the investor because she or he prefers the alternative investment in the capital market. Only investments with $\phi>1$ are favorable. Such investments with positive net present values and, thus, present values $V_{0}^{\tau}>1$ do not fulfill equation (39). We cannot solve this equation theoretically for $\phi>1$ because we face a limit on the value ${ }^{53}$ of $V_{0}^{\tau}$, which never reaches the value $I_{0} \phi$. If we accept a certain deviation of the two present values from each other when determining $z^{\max }$ for $\phi>1$ analytically, the investment must be held for 300 to 7,000 periods to approach an error term of $1 e-8$ to $z^{\max }$. Obviously, if one holding period equals one year, a holding period of this length is unrealistic or at least not relevant to the decision. ${ }^{54}$ Against this background, we conclude that it is not worthwhile to conduct a numerical investigation to obtain a more precise value for $z^{\max }$. Nevertheless, it is worth noting that $Z^{\max }$ is unaffected by the level of capital gains taxation given by $\tau^{g}$, because it cancels out in equation (39). ${ }^{55}$

In the next step, we examine another interesting point in time, when the investor knows that a late exit is as attractive as an immediate exit, i.e., when the present

$52 i \in(0,1), \tau \in[0,1), z \geq 0$.

53 See eq. (33).

54 See Kruschwitz and Löffler (2003) for similar problems with corporations that exist forever. Our results also indicate that there is no optimum holding period; thus, holding forever is an attractive option for the initial investor. This finding is in agreement with business valuation models that determine a minimum price for the seller such that she or he is at least indifferent between selling and holding. Only if the buyer bears the capital gains tax, i.e., pays the capital gains tax in addition to the discounted cash flow value, the vendor will be willing to sell the company.

55 Furthermore, this result enables us to draw conclusions on the impact of transaction costs that so far are disregarded in our setting. We could implement transaction costs in a plausible and simple case into our model as a function of the capital gains and thus a multiplier to the capital gain, similar to $\tau^{g}$ in equation (39). We will correspondingly find that $z^{\max }$ will remain unaffected. 
value for exits later than $z=0$ reaches the present value for an exit at $z=0$ again. Only if late exits are at least as attractive as immediate sales will an investor hold the investment. We define the exit time $z=z^{g}$ with $z^{g} \in\left[0, z^{\max }\right]$, as the point in time at which the present value in case of an exit at $z^{\mathcal{g}}\left(V_{0}^{\tau}\left[z=z^{\mathcal{g}}\right]\right)$ is equal to the present value for an immediate exit at $z=0\left(V_{0}^{\tau}[z=0]\right)$. Only for exit times later than $z^{g}$ does an investment earn more than in the case of an immediate sale, and it should thus be held for a minimum of $z^{g}$ periods. In figure 7, we illustrate $z^{g}$ as the intersection of the present value in the cases of an immediate sale and a sale at $z^{g}$.

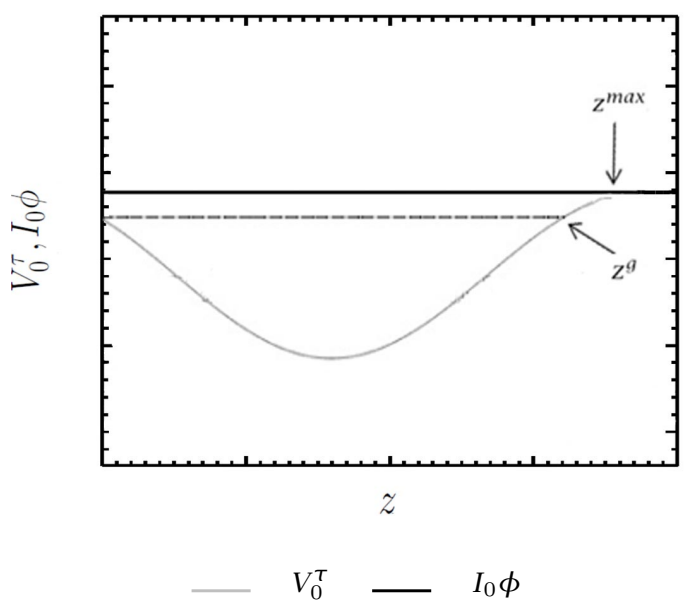

Figure 7: $z^{\max }$ and breakeven exit time $z^{g}$ depending on the time of sale $z$ if $\phi>1$

If $\phi<1,56$ the investor realizes a capital loss at $z=0$ and hence receives a tax refund. This tax refund causes a global maximum value at $z=0$. For later exit times $z>0$, this value $V_{0}^{\tau}[z=0]$ cannot be reached again.

We concentrate on $\phi>1$ because it is the only case in which the present value is greater than 1, and the investment is beneficial, compared to the financial investment. We have $\phi>1$ if the income tax rate is greater than the corporate tax rate. This relationship holds for all tax systems. ${ }^{57}$

We compare $V_{0}^{\tau}[z=0]$ with $V_{0}^{\tau}\left[z=z^{g}\right]$ to answer the question of the exit time $z$ at which the initial value at $z=0$ can be reached again.

\footnotetext{
56 See figure 1 . The investor realizes a capital loss at $z=0$ under the classic corporate tax system and shareholder relief tax system.

57 See Appendix.
} 


$$
\begin{aligned}
& V_{0}^{\tau}[z=0]=V_{0}^{\tau}\left[z=z^{\mathcal{g}}\right] \\
& I_{0} \cdot \phi\left(1-\beta \tau^{g} \cdot\left(1-\frac{1}{\phi}\right)\right)=I_{0} \cdot \phi \cdot\left(1-\beta \tau^{g} \cdot \frac{\left(1+\gamma i^{\tau^{c}}\right)^{z^{g}}-\frac{1}{\phi}}{\left(1+i^{\tau}\right)^{Z^{g}}}\right) \\
& \Leftrightarrow \quad 1-\frac{1}{\phi}=\frac{\left(1+\gamma i^{T^{c}}\right)^{Z^{g}}-\frac{1}{\phi}}{\left(1+i^{\tau}\right)^{z^{g}}} \\
& \Leftrightarrow \quad 0=\frac{\left(1+\gamma i^{\tau^{c}}\right)^{Z^{g}}-\frac{1}{\phi}}{\left(1+i^{\tau}\right)^{Z^{g}}}+\frac{1}{\phi}-1 .
\end{aligned}
$$

For holdings with $z>Z^{g}$ the investment will be better off than in the case of an immediate sale. As already noted for $z^{\max }$ we see that $z^{g}$ is not affected by the capital gains tax rate. Unfortunately, we could not find a method to determine analytically the tangent $z^{g}$ from this equation. In contrast with the $z^{\max }$-function, in equation (41), $z^{g}$ exists at least for $\phi>1$. Hence, we can identify (beneficial) investments that generate after-tax cash flows, which exceed the initial present value at $z=0$ for later sales. Nevertheless, to determine this point in time, we resort to a numerical approach.

\subsection{NUMERICAL ANALYSIS}

Because we cannot calculate $z^{g}$ analytically, we use Newton's method to determine the breakeven point $z^{g}$. Recall that Newton's method is an iterative scheme to compute numerically the zero of an equation of the form $f[x]=0$, given a differentiable function $f .{ }^{58}$

58 This function $f$ determines some $x^{*}$ such that $f\left[x^{*}\right]=0$ holds approximately in the following way. Assume that the first derivative $f^{\prime}[x]$ of $f$ is given, and let $x_{0}$ be an initial guess in some neighborhood of the suspected zero $x^{*}$. Then, compute for $k=0,1,2, \ldots$ the next iterates $x_{k+1}$ by $x_{k+1}=x_{k}-\frac{f\left[x_{k}\right]}{f^{\prime}\left[x_{k}\right]}$. This iteration is terminated when the absolute error satisfies $\left|f\left[x_{k+1}\right]\right|<$ $10^{-8}$, which means that $x_{k+1}$ is very close to the desired zero $x^{*}$. Alternatively, for our numerical experiments, we performed at most 50 iterations, i.e., $k=0, \ldots, 49$. Here, the function $f$ is the right-hand side of the last identity in equation (41). 
We assume the following parameters:

\begin{tabular}{l|l} 
parameter & value \\
\hline$I_{0}$ & 1 \\
$i$ & 0.1 \\
$\tau^{\mathcal{C}}$ & $0.4(\mathrm{FI})$ and 0.25 (SR and CC) \\
$\tau$ & 0.5 \\
$\tau^{\mathcal{g}}$ & $\frac{\tau}{2}$ (FI and CC) and $\tau$ (SR)
\end{tabular}

Table 1: Data for the numerical example

In the following, we denote $z^{g}$ as a breakeven point. From this point of time, it is beneficial for the investor to hold the investment.

The assumed tax rates are based on real-world tax rates. ${ }^{59}$ We assume an income tax rate of $\tau=0.5$, according to the average marginal tax rate in Germany (19902012). ${ }^{60}$ The capital gains tax rate is linked to the income tax rate. If the underlying tax system requires a uniform income tax rate on dividends and interest $(\beta=1)$, we set $\tau^{\mathcal{g}}=\frac{\tau}{2}$. If the tax system is characterized by a preferential lower income tax rate on dividends, we set $\beta=0.5$ and $\tau^{g}=\tau$. Under all of the tax systems, capital gains are assumed to be tax-exempt.

59 In the German full imputation tax system, the corporate tax rate from 1999 until 2000 was $40 \%$. Within the shareholder relief tax system, the corporate tax rate was $25 \%$. We choose the same tax rate for the classic corporate tax system.

60 The top marginal income tax rates in Germany were as follows: 1990-1999: 53\%, 2005: 42\% and $201245 \%$. Considering the solidarity surcharge, it currently sums up to $0.475 \%$ 
Figure 8 displays $z^{g}$ as a result of the Newton iteration for the three tax systems and different retention rates $\gamma$.

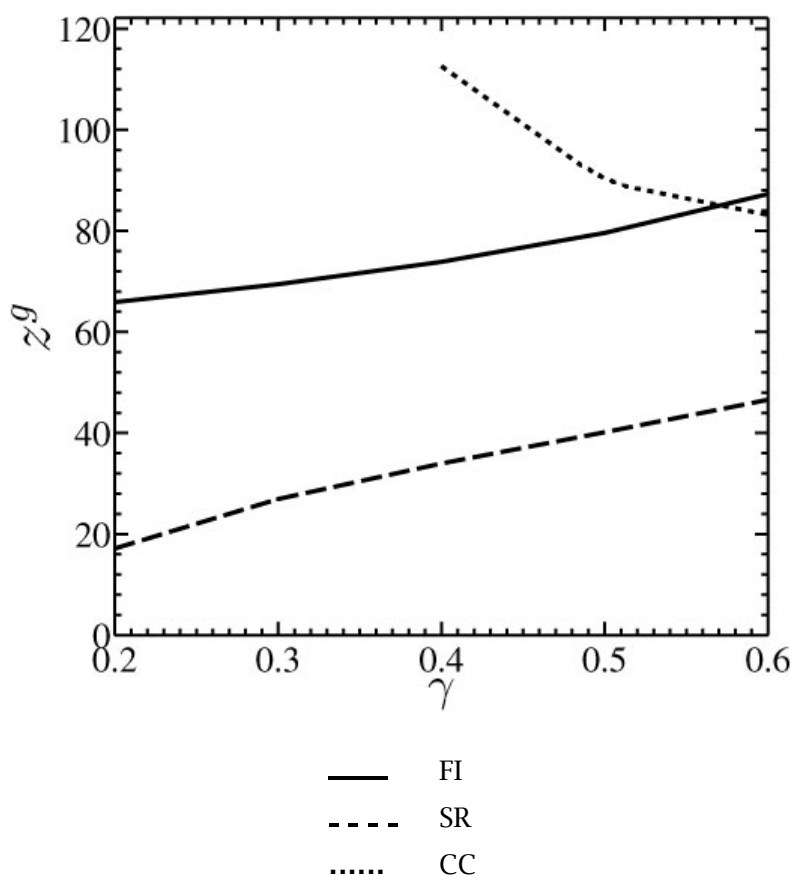

Figure 8: Breakeven exit time $z^{g}$ depending on the retention rate $\gamma$

Figure 8 illustrates that, e.g., under the full imputation (shareholder relief) tax system with a retention rate of $\gamma=0.2$, the investment yields the present value given for $z=0$ after 66 (17) periods (years), while it takes 87 (47) periods (years) for a high retention rate of $\gamma=0.6 .^{61}$

If we assume that the investor strives to reach the breakeven point $\left(z^{g}\right)$ as quickly as possible and that the preferred tax system depends on the profit distribution, the development of the profit distribution is essential for the investor. Under full imputation and shareholder relief, $V_{0}^{\top}$ can be realized for earlier exits at low retention rates. By contrast, under the classic corporate tax system, we observe high retention rates to stimulate an earlier breakeven point. ${ }^{62}$

To understand properly the mechanisms at work, we must separate the driving forces. Interest, captured in the discount factor, is taxed equally under all three sys-

61 See also Protopapadakis (1983), who estimates average holdings periods of 21 to 34 years.

62 Under the classic corporate tax system for retention rates smaller than 0.4 , a disadvantageous present value emerges, which we exclude. See section 3.4. 
tems. The capital gains tax rate is the same under all three systems as well. The difference is due to corporate taxation, dividend taxation and, thus, also to taxes that have reduced accumulated capital gains, which will be tax-liable at sale.

Under the full imputation tax system, the capital gains tax burden exceeds taxes on dividends. ${ }^{63}$ With an increasing retention rate, the present value decreases, and the growth effect can only later be compensated for the discount effect. These effects delay $z^{g}$.

Under the shareholder relief tax system, dividends and capital gains are subject to the same tax rate. Nevertheless, capital gains taxation occurs later, and multiple taxation of profits is likely to occur: both types of capital income are taxed at a corporate tax rate of $25 \%$. Dividends are subject to a capital income tax of $25 \%$ during the same period. Capital gains are taxed at $25 \%$ at the time of sale $z$. Note that the capital gains tax basis has been affected by the anticipated dividend tax of investor B. Capital gains are therefore at a tax disadvantage, particularly for high retention rates. Thus, the breakeven point, $z^{\mathfrak{g}}$, is reached even later.

Under the classic corporate tax system, the tax burden for capital gains is smaller than for dividends. ${ }^{64}$ This tax advantage leads to an increase in the present value for increasing retention rates. Consequently, the breakeven point $z^{g}$ is reached earlier.

The temporary difference in $z^{g}$ is higher for small retention rates. This result is consistent with our results for the worst exit time. ${ }^{65}$

We find that from the investor's perspective, a change in the tax system, as well as in the retention policy, affects the tax-optimal holding strategies. Under shareholder relief, an early breakeven point results from a low retention rate, whereas low retention rates cause a late breakeven point under a classic corporate tax system in countries that have changed their tax systems from classic corporate taxation to shareholder relief tax systems as, e.g., the Netherlands in 2001, the United States in 2003 and

63 The corporate taxation can be imputed only against the income tax on dividends.

64 Dividends are taxed without tax shield with a tax rate of $50 \%$, and capital gains are taxed at a rate of $25 \%$.

65 To highlight the relevance of the assumed range of retention rates, we give an example. If we look at the annual reports McDonald's Corporation (2011) and McDonald's Corporation (2013), we find a retention ratio of, e.g., $24 \%$ in $2007,57 \%$ in 2008 and $44 \%$ in 2013 . Relating to the example above, which is characterized by similar dividend rates, the holding period, which is necessary for a beneficial investment, varies between 17 (shareholder relief tax system, $\gamma=0.2$ ) and 113 (classic corporate tax system, $\gamma=0.4$ ) periods. 
Switzerland in 2007.66 These reforms emphasize the relevance of our findings. In countries with such tax reforms, the breakeven exit time has changed dramatically in the aftermath of reform.

To illustrate the influence of capital gains taxation in a different manner, figure 9 depicts the relative difference between the present values without and with capital gains taxation $\left(\frac{\phi-V_{0}^{\tau}}{\phi}\right.$ relative capital gains tax wedge) for an immediate exit at $z=0$.

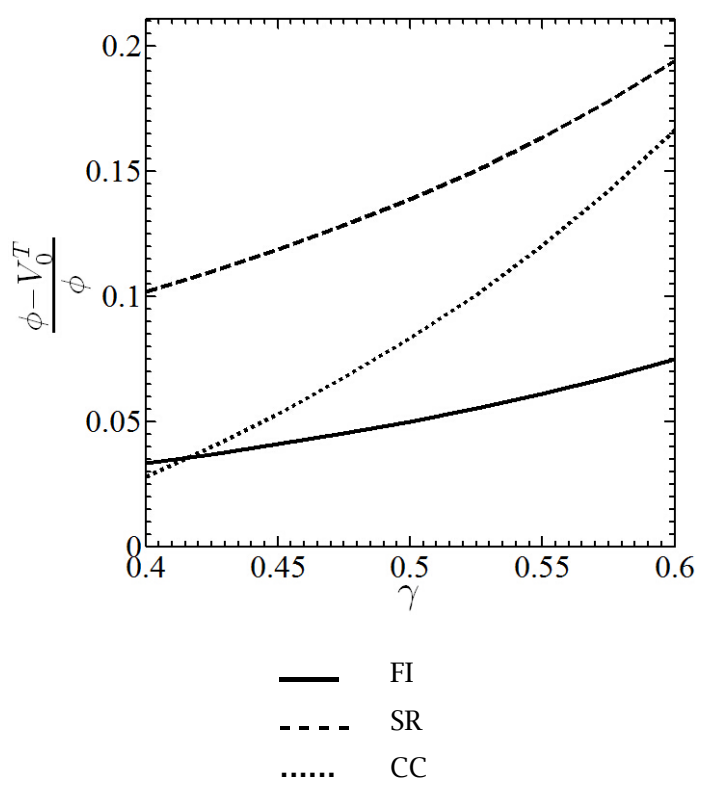

Figure 9: Relative capital gains tax wedge $\frac{\phi-V_{0}^{\tau}}{\phi}$ for different tax systems and various retention rates $\gamma$ with $\tau=0.5$ and $z=0$

Although this setting is stylized, the illustration of the present value with an exit time in $z=0$ enables us to abstract from the time effects of capital gains taxation, e.g., the growth and discount effects. Here, we only capture the effects of capital gains taxation independent of the exit time.

Obviously, the greatest difference occurs under the shareholder relief tax system; i.e., the distortion of capital gains taxation is highest in this tax system. The differences in all of the tax systems increase with retention rates. This development is due to the greater influence of capital gains taxation. The reason for this development is the present value without capital gains taxation $(\phi)$. The higher that $\phi$ is, the larger the distortion of capital gains taxation is. A closer consideration of the

66 See Becker et al. (2013), p. 6. 
value of $\phi$ is appropriate: From a tax perspective, $\phi$ is affected by income tax and corporate tax. Retained earnings are most intensively taxed under a full imputation tax system because a corporate tax rate of $40 \%$ is applicable, while the other systems are characterized by a corporate tax rate of $25 \%$. Dividends are most taxed under the classic corporate tax system at a corporate tax rate of $25 \%$ and income tax rate of $50 \%$, without tax exemptions. ${ }^{67}$ Moderate taxation under shareholder relief leads to the highest present value without capital gains, which is crucial to the maximum deviation between the present value without and with capital gains taxation $\left(\frac{\phi-V_{0}^{\tau}}{\phi}\right)$ in a shareholder relief tax system. ${ }^{68}$

If examined at $V_{0}^{\tau}$, capital gains are taxed differently in these three tax systems. The steep slope of the classic corporate curve is remarkable, and the retention rate for the classic corporate tax system is the most influential. In the classic corporate tax system, capital gains taxation is most powerful. Here, capital gains are not tax exempted, and the tax base is relatively high with regard to a corporate tax rate of $25 \%$. The slope of the full imputation curve is flat. Indeed, capital gains are not tax exempted, but the capital gains themselves are smallest relative to the high corporate tax rate of $40 \%$. The slope of the shareholder relief tax system is similar to the full imputation tax system. In this system, capital gains are indeed higher than under full imputation, ${ }^{69}$ but only half of the capital gains is taxed.

\section{CONCLUSION}

Because investments are often characterized by entry and exit flexibility, investors must make decisions about both the investment and holding periods. Both decisions are typically affected by corporate, income and capital gains taxation. Focusing on investment in corporate shares, we investigate the impact of capital gains taxation on the holding period under three different tax systems and thus how long investors should hold their stocks.

67 By contrast, under a full imputation system, dividends are only subject to the income tax at $50 \%$ and under shareholder relief to the corporate tax at a rate of $25 \%$, and only half of the dividends are subject to the income tax.

68 See figure 9.

69 Note that the corporate tax rate in the shareholder relief tax system is $25 \%$. 
However, we find that there is no optimal holding period for a present valuemaximizing investor. We analytically derive a worst exit time that should be avoided by investors, and we show that an immediate sell-off often is more attractive than a short holding period. Nevertheless, if an investor wants to hold these stocks for a longer period of time, she or he is well advised to wait until the breakeven exit time, i.e., until the present value of an immediate sell-off can be recovered. We determine the breakeven time, at which a late exit is as attractive as an immediate exit. Because there is no analytical solution to the problem, we provide a numerical solution.

Our findings confirm the results in prior research that capital gains taxation is likely to foster longer holdings (lock-in effect) and thereby to stimulate long-term investment. We find that capital gains taxation delays exit decisions, but the decision relevance of capital gains taxation vanishes for very long holdings. Hence, our results indicate that the capital gains tax lock-in effect is only temporary. Furthermore, we show that the breakeven exit period crucially depends on the degree of income and corporate tax integration. A classic corporate tax system often induces holdings over more than 100 periods. Our results indicate that shareholder relief allows shareholders who aim for medium- or long-term investment horizons the earliest profitable sales. Hence, shareholder relief provides the greatest degree of exit time flexibility among the three underlying tax systems. Surprisingly, high retention rates are likely to accelerate sales under the classic system. By contrast, under full imputation and shareholder relief the required breakeven holding period increases with the retention rate.

Furthermore, we clarify that the worst exit time differs considerably across the three underlying tax systems if the retention rate is low. For an integrated tax system with full imputation, it is reached earlier than under partial or non-integrated systems. Although long-term investments often seem to be superior to short-term investments from an investor's post-tax, present value perspective, our study also emphasizes that capital gains taxation often renders investments disadvantageous overall.

Our results are characterized by several limitations, for example, the focus on capital gains due to profit retention only. We abstract from other sources of capital gains, such as speculative bubbles. Moreover, our findings are limited by the assumption of uniform capital gains tax rates for short- and long-term capital gains. Under the given set of assumptions, short-term investments become disadvantageous such that 
investors will refrain from them under all three tax systems. If we extend our model and implement differentiating capital gains tax rates, short-term investments will become even more unfavorable because they suffer from higher capital gains tax rates. However, we cannot draw normative conclusions from this result. Our model does not capture aspects that enable us to conclude that short-term investments are less desirable (bad, i.e., speculative) for an economy than long-term (good, i.e., sound) investments, which in turn could justify such distortions.

Nevertheless, according to prior conclusions on the aggregate level, for example, using a general equilibrium model, tax reformers must anticipate investors' reactions at the micro level. While tax politicians might prefer longer holdings to motivate persistent investments, such a strategy might also be inefficient. Tax reformers must be aware that the underlying tax system and the retention rate influence the breakeven point and the worst exit time of investment significantly.

Hence, our results could help to predict investors' behavior with regard to changes in capital gains taxation, depending on the degree of corporate and income tax integration: thus, they will be interesting to both investors and tax policymakers. Our findings provide a theoretical basis for empirical tests of the derived predictions of holding behavior conditioned on the underlying tax system. Furthermore, they emphasize the need to control for the respective tax systems in cross-country empirical studies. 


\section{REFERENCES}

Alles, Lakshman and Murray, Louis (2009). Investment Performance and Holding Periods: An Investigation of the Major UK Asset Classes, Journal of Asset Management, 10 (5), 280-292.

Auerbach, Alan J. (1989). Capital Gains Taxation and Tax Reform, National Tax Journal, 42 (3), 391-401.

- (1991). Retrospective Capital Gains Taxation, The American Economic Review, $81(1), 167-178$.

Ayers, Benjamin C.; Lefanowicz, Craig E. and Robinson, John R. (2003). Shareholder Taxes in Acquisition Premiums: The Effect of Capital Gains Taxation, The Journal of Finance, 58 (6), 2783-2801.

Ayers, Benjamin C.; Li, O Z. and Robinson, John R. (2008). Tax-Induced Trading around the Taxpayer Relief Act of 1997, Journal of the American Taxation Association, 30, 77-100.

Becker, Bo; Jacob, Marcus and Jacob, Martin (2013). Payout Taxes and the Allocation of Investment, Journal of Financial Economics, 107 (1), 1-24.

Blouin, Jennifer L.; Raedy, Jana Smith and Shackelford, Douglas A. (2002). Equity Price Pressure from the 1998 Reduction in the Capital Gains Tax Holding Period, Journal of the American Taxation Association, 24 (2), 70-93.

BMF (2013). Die wichtigsten Steuern im internationalen Vergleich 2012., https://www.bundesfinanzministerium.de/Content/DE/Downloads/Broschueren _Bestellservice/2013-04-15-wichtigste-steuern-vergleich-2012.pdf?blob=publication_File\&v=7. Accessed 13 October 2014.

Bogart, William T. and Gentry, William M. (1995). Capital Gains Taxes and Realizations: Evidence from Interstate, The Review of Economics and Statistics, 77 (2), 267-282.

Bradford, David F. (1981). The Incidence and Allocation Effects of a Tax on Corporate Distributions, Journal of Public Economics, 15 (1), 1-22.

Brandstetter, Laura and Jacob, Martin (2014). Do Corporate Tax Cuts Increase Investments?. FAccT Center Working Paper, doi:10.2139/ssrn.1825147. 
Campbell, John L.; Chyz, James A.; Dhaliwal, Dan S. and Schwartz, William C. Jr. (2013). Did the 2003 Tax Act Increase Capital Investments by Corporations?, Journal of the American Taxation Association, 35 (2), 33-63.

Carroll, Robert; Pizzola, Brandon; Hultmann, Erik and Segerström, Martin (2012). Corporate Dividend and Capital Gains Taxation: A comparison of Sweden to other member nations of the OECD and EU, and BRIC countries., http://www.svensktnaringsliv.se/migration_catalog/Rapporter_och_opinionsmaterial/Rapporters/corporate-dividend-and-capital-gains-taxation-a-comparisonof-swe_533034.html/binary/Corporate\%20Dividend\%20and\%20Capital\%20Gains\%20 Taxation\%20-\%20A\%20comparison\%20of\%20Sweden\%20to\%20other\%20member\%20 nations\%20of\%20the\%20OECD\%20and\%20EU,\%20and\%20BRIC\%20countries.pdf. Accessed 13 October 2014.

Cheng, Ping; Lin, Zhenguo and Liu, Yingchun (2010). Illiquidity, Transaction Cost, and Optimal Holding Period for Real Estate: Theory and Application, Journal of Housing Economics, 19, 109-118.

Constantinides, George M. (1983). Capital Market Equilibrium with Personal Tax, Econometrica, 51 (3), 611-636.

Cook, Eric W. and O'Hare, John F. (1987). Issues Relating to the Taxation of Capital Gains, National Tax Journal, 40, 473-488.

Cremer, Helmuth; Gahvari, Firouz and Ladoux, Norbert (2010). Income Tax Reform in France: A Case Study, FinanzArchiv/Public Finance Analysis, 66 (2), 121-133.

Dai, Zhonglan; Maydew, Edward; Shackelford, Douglas A. and Zhang, Harold H. (2008). Capital Gains Taxes and Asset Prices: Capitalization or Lock-in?, The Journal of Finance, 63 (2), 709-742.

Diller, Markus and Theelen, Thomas (2014). Do Tax-Induced Share-Deal Price Discounts Exit? Evidence from German Privately Held Target Companies, 74 (4), 215236.

Edwards, Chris (2012). Advantages of Low Capital Gains Tax Rates, Tax \& Budget Bulletin, December, 1-5. 
Ehling, Paul; Gallmeyer, Michael; Srivastava, Sanjay; Tompaidis, Stathis and Yang, Chunyu (2013). Portfolio Choice with Capital Gain Taxation and the Limited Use of Losses. EFA 2008 Athens Meetings Paper; McCombs Research Paper Series., doi:10.2139/ssrn.1003034.

Fatemi, Ali and Bildik, Recep (2012). Yes, Dividends are Disappearing: Worldwide Evidence, Journal of Banking \& Finance, 36 (3), 662-677.

Feldstein, Martin; Slemrod, Joel and Yitzhaki, Shlomo (1980). The Effects of Taxation on the Selling of Corporate Stock and the Realization of Capital Gains, Quarterly Journal of Economics, 94 (4), 777-791.

Frère, Eric; Röhl, Christian W. and Schyra, Andreas (2012). dips/DSW Dividendenstudie 2012, http://www.fom.de/fileadmin/fom/presse_aktuell/PDFs/dips_DSW _Dividendenstudie_2012.pdf. Accessed 13 October 2014.

Gau, George W. and Wang, Ko (1994). The Tax-Induced Holding Periods of Real Estate Investors: Theory and Empirical Evidence, Journal of Real Estate Finance and Economics, 8, 71-85.

Gordon, Myron J. (1962). The Savings Investment and Valuation of a Corporation, The Review of Economics and Statistics, 44 (1), 37-51.

Gordon, Myron J. and Shapiro, Eli (1956). Capital Equipment Analysis: The Required Rate of Profit, Management Science, 3 (1), 102-110.

Graham, John R. (2008). Taxes and Corporate Finance, In: Eckbo BE (ed) Handbook of Corporate Finance: Empirical Corporate Finance,, 2nd edn. North-Holland, Amsterdam, pp 59-133.

Guenther, David A. and Sansing, Richard (2006). Fundamentals of Shareholder Tax Capitalization, Journal of Accounting and Economics, 42 (3), 371-383.

ap Gwilym, Owain; Seaton, James; Suddason, Karina and Thomas, Stephen (2006). International Evidence on the Payout Ratio, Earnings, Dividends, and Returns, Financial Analysts Journal, 62 (1), 36-53.

Haesner, Christian and Schanz, Deborah (2013). Payout Policy Tax Clienteles, Exdividend Day Stock Prices and Trading Behavior in Germany: The Case of the 2001 Tax Reform, Journal of Business Finance \& Accounting, 40 (3-4), 527-563. 
Halberstadt, Alexander; Sureth, Caren and Armin, Voß (2009). Der Einfluss der Abgeltungssteuer auf die Vorteilhaftigkeit von Anlagen in Genussscheine und Aktien, Die Wirtschaftsprüfung, 62 (6), 373-381.

Hanlon, Michelle and Heitzman, Shane (2010). A Review of Tax Research, Journal of Accounting and Economics, 50 (2-3), 127-178.

Hundsdoerfer, Jochen; Kiesewetter, Dirk and Sureth, Caren (2008). Forschungsergebnisse in der Betriebswirtschaftlichen Steuerlehre - eine Bestandsaufnahme, Zeitschrift für Betriebswirtschaft/Journal of Business Economics, 78 (1), 61-139.

Ivković, Zoran; Poterba, James and Weisbenner, Scott (2005). Tax-Motivated Trading by Individual Investors, American Economic Review, 95 (5), 1605-1630.

Jacob, Marcus and Jacob, Martin (2013). Taxation and the Cash Flow Sensitivity of Dividends, Economics Letters, 118 (1), 186-188.

Jacob, Martin (2013). Capital Gains Taxes and the Realizations of Capital Gains and Losses - Evidence from German Income Tax Data, FinanzArchiv/Public Finance Analysis, 69 (1), 30-56.

- (2014). Tax Regimes and Capital Gains Realizations. FAccT Center Working Paper, doi:10.2139/ssrn.1825147.

Klein, Peter (1999). The Capital Gain Lock-In Effect and Equilibrium Returns, Journal of Public Economics, 71 (3), 355-378.

Knoll, Leonard and Wenger, Ekkehard (2007). The New German Reform Act: A Critical Assessment, Tax Notes International, 47, 353-356.

König, Rolf and Wosnitza, Michael (2000). Zur Problematik der Besteuerung privater Aktienkursgewinne - eine ökonomische Analyse, Zeitschrift für Betriebswirtschaft/Journal of Business Economics, 70, 781-801.

König, Rolf and Wosnitza, Michael (2004). Betriebswirtschaftliche Steuerplanungs- und Steuerwirkungslehre, Physica, Heidelberg.

Kruschwitz, Lutz and Löffler, Andreas (2003). Zur Bewertung ewig lebender Unternehmen mit Hilfe von DCF-Verfahren, Der Betrieb, 56 (26), 1401-1402. 
Lang, Mark H. and Shackelford, Douglous A. (2000). Capitalization of Capital Gains Taxes: Evidence from Stock Price Reaction to the 1997 Rate Reduction, Journal of Public Economics, 76 (1), 69-85.

McDonald's Corporation (2011). Annual Report 2011., http://www.aboutmcdonalds.com/ content/dam/AboutMcDonalds/Investors/Investors\%202012/2011\%20Annual\%20Re port\%20Final.pdf. Accessed 13 October 2014.

- (2013). Annual Report 2013., http://www.aboutmcdonalds.com/ content/dam/AboutMcDonalds/Investors/McDs2013AnnualReport.pdf. Accessed 13 October 2014.

Müller, Heiko and Semmler, Birk (2003). Steuerbedingter Kaufpreisabschlag bei Anteilen an einer Kapitalgesellschaft, 73 (6), 583-599.

Niemann, Rainer and Sureth, Caren (2013). Sooner or Later? - Paradoxical Investment Effects of Capital Gains Taxation Under Simultaneous Investment and Abandonment Flexibility, European Accounting Review, 22 (2), 367-390.

Nippel, Peter and Podlech, Nils (2011). Die Entscheidung über den Verkauf von Wertpapieren unter der Abgeltungssteuer und auf Basis subjektiver Erwartungen, Zeitschrift für Betriebswirtschaft/Journal of Business Economics, 81 (5), 519-549.

OECD (2014). Revenue Statistics, 1965-2013, Paris, doi:10.1787/9789264235120-en.

Pomerleau, Kyle (2014). The High Burden of State and Federal Capital Gains Tax Rates, Tax Foundation, February, 1-8.

Poterba, James M. and Weisbenner, Scott J. (2001). Capital Gains Tax Rules, Tax-loss Trading, and Turn-of-the-year Returns, The Journal of Finance, 56 (1), 353-368.

Protopapadakis, Aris (1983). Some Indirect Evidence on Effective Capital Gains Tax Rates, Journal of Business, 56 (2), 127-138.

Rupp, Kristina (2012). Analytische und numerische Berechnungen zur Optimierung des Einflusses von Besteuerung auf Unternehmensentscheidungen, Diploma Thesis, University of Paderborn (available by E-Mail from the author or A. Kunoth). 
Schanz, Deborah and Schanz, Sebastian (2011). Business Taxation and Financial Decisions, Springer, Berlin and Heidelberg.

Schreiber, Ulrich and Rogall, Matthias (2000). Der Einfluss der Reform der Körperschaftsteuer auf Investitionsentscheidungen und den Wert der Gewinnrücklagen von Kapitalgesellschaften, Die Betriebswirtschaft, 60 (6), 721-737.

Shackelford, Douglas A. and Shevlin, Terry (2001). Empirical Tax Research in Accounting, Journal of Accounting and Economics, 31 (1-3), 321-387.

Stiglitz, Joseph E. (1983). Some Aspects of the Taxation of Capital Gains, Journal of Public Economics, 21 (2), 257-294.

Sureth, Caren (2003). Die Besteuerung von Beteiligungsveräußerungen und Rechtsformneutralität, Zeitschrift für Betriebswirtschaft/Journal of Business Economics, $73(8), 793-824$.

- (2006). Steuerreformen und Übergangsprobleme bei Beteiligungsinvestitionen, Deutscher Universitätsverlag, Wiesbaden.

Sureth, Caren and Langeleh, Dirk (2007). The Degree of Integrating Corporate and Capital Gains Tax into Income Tax and its Impact on Investment Decisions, Schmalenbach Business Review, 59 (4), 310-339. 


\section{APPENDIX}

For the full imputation tax system $\alpha=0, \beta=1$. Hence we obtain ${ }^{70}$

$$
\begin{aligned}
& \phi>1 \\
& \Leftrightarrow \quad \frac{(1-\beta \tau)(1-\gamma)\left(1-\alpha \tau^{\mathcal{C}}\right)}{(1-\tau)-\gamma\left(1-\tau^{\mathcal{C}}\right)}>1 \\
& \Leftrightarrow \quad(1-\tau)(1-\gamma)>(1-\tau)-\gamma\left(1-\tau^{\mathcal{C}}\right) \\
& \Leftrightarrow \quad(1-\tau)((1-\gamma)-1)>-\gamma\left(1-\tau^{c}\right) .
\end{aligned}
$$

As $\gamma \neq 0$

$$
\begin{array}{rlrl} 
& 1-\tau<1-\tau^{c} \\
\Leftrightarrow & \quad & T>T^{c} .
\end{array}
$$

Under the shareholder relief tax system $\alpha=1, \beta=0.5$ and thus ${ }^{71}$

$$
\begin{array}{rlrl}
\phi & >1 \\
\Leftrightarrow & \frac{(1-0.5 \tau)(1-\gamma)\left(1-\tau^{c}\right)}{(1-\tau)-\gamma\left(1-\tau^{c}\right)} & >1 \\
\Leftrightarrow & -\frac{0.5 \tau\left(1+\tau^{c}\right)-\tau^{c}}{0.5 \tau\left(1-\tau^{c}\right)} & <\gamma .
\end{array}
$$

Since $\gamma<\frac{i^{\tau}}{i^{T^{c}}}$ we obtain

$$
\begin{array}{rlrl} 
& & -\frac{0.5 T\left(1+\tau^{c}\right)-\tau^{c}}{0.5 T\left(1-T^{c}\right)} & <\frac{(1-\tau) i}{\left(1-T^{c}\right) i} \\
\Leftrightarrow & -0.5 \tau-0.5 \tau \tau^{c}+\tau^{c} & <0.5 \tau-0.5 \tau^{2} \\
\Leftrightarrow & & (-0.5 \tau+1) \tau^{c} & <(-0.5 \tau+1) \tau^{2} \\
\Leftrightarrow & & \tau & >\sqrt{T^{c}} \geq \tau^{c} .
\end{array}
$$

From $0 \leq \tau^{c}<1$ follows

$$
\tau>\tau^{c} .
$$

70 See Sureth (2006), pp. 75ff., and Rupp (2012), p. 46.

71 See Sureth (2006), pp. 97ff., and Rupp (2012), p. 48. 
For the classic corporate tax system we have to set $\alpha=1, \beta=1$ and get ${ }^{72}$

$$
\begin{array}{rlrl}
\phi & >1 \\
\Leftrightarrow \quad & \frac{(1-\beta T)(1-\gamma)\left(1-\alpha \tau^{c}\right)}{(1-\tau)-\gamma\left(1-\tau^{c}\right)} & >1 \\
\Leftrightarrow & \gamma & >\frac{T^{c}(1-\tau)}{\tau\left(1-\tau^{c}\right)} .
\end{array}
$$

Given that $\gamma<1$ we can write

$$
\begin{array}{rlrl} 
& & & >\frac{\tau^{c}(1-\tau)}{\tau\left(1-\tau^{c}\right)} \\
\Leftrightarrow & T\left(1-\tau^{c}\right) & >T^{c}(1-\tau) \\
\Leftrightarrow & & \tau & >T^{c} .
\end{array}
$$

72 See Rupp (2012), p. 52. 